\title{
Resumen
}

En buena parte de los estudios relacionados con seguridad pública en el país predominan los análisis desde un nivel macro, con un acento centralista y con énfasis en las políticas y medidas que se implementan desde el Ejecutivo. Es por ello que el presente artículo se enfoca en la dimensión local de las políticas de seguridad pública, retomando la importancia de las municipalidades en la gestión e implementación de éstas, principalmente en un momento en que la presencia territorial del Estado está siendo contestada por agrupaciones criminales. En tal sentido, se analiza el rol estratégico que los Cuerpos de Agentes Municipales (CAM) podrían tener en los esfuerzos de prevención de la violencia y el crimen, así como en los de recuperación de la presencia estatal en el territorio, planteando las imprecisiones y los impedimentos jurídicos, así como los políticos, que aún no permiten que éstos tengan una función más determinante en la seguridad y el desarrollo local. \section{seguridad pública \\ Análisis sobre los cuerpos de agentes municipales y su rol en la} Marlon Hernández-Anzora San Salvador, El Salvador mihanzora@gmail.com

Walter Murcia San Salvador, El Salvador waltermurc@gmail.com

\section{Palabras clave}

Seguridad, gobiernos locales, cuerpo de agentes municipales, prevención, control social y territorial.

Recibido: Diciembre 16 de 2015 Aceptado: Febrero 15 de 2016

BIBLID [2225.5648 (2016), 6:1, 83.126] DOI: dx.doi.org/10.5377/rpsp.v6i1.2699 


\begin{abstract}
:
In many of the studies related to public security in the country the macro level analysis dominates, with a centralist accent and an emphasis on policies and measures implemented by the Executive Branch. Reason why this article focuses on the local dimension of public security policies, highlighting the importance of municipalities in the management and implementation of these policies, especially at a time when the territorial presence of the state was undertaken by criminal groups. In this sense, the strategic role of the Municipal Agents Corp (CAM) in violence and crime prevention will be analyzed, as well as the recovery of state presence in the territory, stating the inaccuracies and legal impediments, including politicians, who do not allow this corps to have a more decisive role in security and local development.
\end{abstract}

\title{
Key words:
}

Security, local governments, municipal body agents, prevention, social and territorial control.

Received: December 16, 2015

Accepted: February 15, 2016 


\section{Introducción}

En los últimos años, en respuesta a los desafíos que enfrentan los Estados en materia de inseguridad y violencia, se ha formulado y puesto en práctica una serie de enfoques holísticos en materia de seguridad pública que, separándose de concepciones tradicionales de carácter punitivo-represivo, reconocen que, para tratar fenómenos tan complejos y multicausales como son el crimen y la violencia, se requieren de respuestas multidimensionales que incorporen, además de los componentes de control y represión, la prevención social del delito. A partir de estos enfoques integrales se apuesta por la coproducción y corresponsabilidad en la gestión de los temas de seguridad pública y desarrollo.

En ese marco, cada vez son más las ciudades a lo largo del planeta que han puesto en marcha diferentes programas gestados en el entorno local y dirigidos a la prevención de la delincuencia, iniciativas que buscan mejorar las condiciones de vida en los espacios que ocupan sus habitantes (Ruiz Rodríguez, 2010). Desde esa perspectiva, se revaloriza y se le asigna un rol clave a la dimensión local en las políticas de seguridad, reconociendo que son las autoridades locales, en representación del Estado, a las que en un primer momento les compete brindar respuestas a las problemáticas de violencia y delincuencia que ocurren en sus municipios (Acero Velásquez, s.f.).

En los países de América Latina, es posible identificar una serie de experiencias que asignan un peso importante a los gobiernos locales en la gestión e implementación de las políticas de seguridad pública. Así han sido los procesos desarrollados en ciudades como Bogotá, Medellín, Quito, Guayaquil, Sao Paulo, Managua, en los que sobresalen el liderazgo de sus gobiernos locales para implementar estrategias integrales de seguridad basadas en el fortalecimiento de las capacidades de las instituciones de seguridad y justicia (entre ellas la policía metropolitana), en la recuperación de espacios públicos, una fuerte inversión en prevención de la violencia juvenil, entre otros aspectos. Todo ello ha posibilitado no solo bajar los índices de homicidios y criminalidad, sino que también ha aumentado los niveles de convivencia ciudadana y sentado las bases para la transformación y desarrollo de dichas urbes.

Al analizar el caso de El Salvador y el peso que tiene la dimensión local en las políticas de seguridad, lo primero que salta a la vista es que, si bien los Acuerdos de Paz (1992) establecieron un nuevo esquema de seguridad pública-a partir del cual se determinó que el resguardo de la paz, la tranquilidad, el orden y la seguridad pública estarían a cargo de la Policía Nacional Civil (PNC)—, no obstante, en los últimos años, las estrategias gubernamentales de seguridad pública—como ha sido la Política Nacional de Justicia, Seguridad Pública y Convivencia (Ministerio de Justicia y 
Seguridad Pública, s. f.)—otorgan un rol cada vez más estratégico a los gobiernos locales en los esfuerzos de prevención social de la violencia y el crimen.

En esas estrategias, los cuerpos de agentes municipales (CAM), lo más cercano a un tipo de policía municipal, como se le conoce en otros países, pese al limbo jurídico en el que operan, además de cumplir con su función principal de velar por el resguardo del patrimonio municipal, en la práctica -ya sea directa o indirectamente- realizan dentro de sus funciones acciones en materia de prevención del delito y el crimen.

Teniendo en cuenta que el objeto de estudio de este análisis son los CAM, hay que reconocer que en El Salvador han predominado los análisis e investigaciones sobre seguridad pública desde un nivel macro con un acento centralista, es decir con el énfasis puesto en las políticas y medidas que se implementan desde el Ejecutivo. En cambio, no se puede decir lo mismo respecto a los aportes académicos sobre el rol de otros actores institucionales, como los CAM, en los temas de seguridad pública.

A excepción de algunas tesis universitarias, se trata de un tema del que escasamente se ha investigado de forma sistemática y del que pocos se atreven a opinar, debido a las connotaciones de carácter político que rodean a dicho cuerpo. En buena medida, ello se explica por la visión política y normativa que predomina desde la firma de los Acuerdos de Paz en los temas de seguridad pública. En ese sentido, con este estudio se pretende aportar a ese vacío de investigación, realizando una aproximación (big picture) al rol que cumplen dichos cuerpos, y resaltando algunas rutas y sinergias potenciales entre los CAM y la PNC para garantizar la seguridad de las localidades.

El alcance temporal del estudio es de un período de 10 años, comprendidos entre 2005 y 2015, prestando especial atención a las experiencias del CAM en los municipios de San Salvador, en el departamento de San Salvador, y Santa Tecla, en el departamento de La Libertad. Se trata de dos municipios de los más importantes a nivel nacional que concentran una importante cantidad de población, actividad económica y comercial, así como también una serie de retos y desafíos en materia de seguridad pública. Es importante mencionar que, a pesar de que el estudio se focalizó en estos dos municipios, una parte importante del análisis y de las conclusiones buscan aportar elementos aplicables a nivel nacional, con los respectivos matices locales cuando es pertinente.

Los objetivos planteados para la investigación fueron los siguientes: (1) analizar las dimensiones legales y funcionales que rigen el desempeño de Ios CAM; (2) evaluar la capacidad organizativa, despliegue y operatividad de los CAM en los casos que serán estudiados; (3) describir la relación 
actual de los CAM y la PNC en el control del territorio, combate y prevención de la violencia y delincuencia; y, (4) vislumbrar rutas potenciales para generar mayores sinergias interinstitucionales entre los CAM y la PNC para el control del delito en el marco de estrategias integrales de seguridad pública.

El análisis de este estudio se ha estructurado en cuatro partes. Primero, se realiza una revisión del marco jurídico general en el que operan los CAM. En segundo lugar, se hace referencia a las funciones que en la práctica realizan los CAM y la relación de estas instituciones con la PNC. En una tercera parte, se presenta una serie de elementos que justifica en un nivel estratégico-político la gestión de la seguridad pública, para avanzar en la construcción de mayores sinergias entre PNC y CAM; se toma en cuenta que las estrategias de seguridad pública que se han implementado ponen especial énfasis en los esfuerzos de prevención de la violencia y el delito sobre la base de mecanismos de coordinación interinstitucional y sectorial para responder de manera integral a las manifestaciones de la violencia e inseguridad. A manera de cierre, se plantean algunas consideraciones sobre los desafíos y limitantes que se presentan a la hora de pensar en un posible empoderamiento de los CAM en la seguridad pública en El Salvador.

\section{Marco teórico}

\subsection{Lo global-local, las capacidades del Estado y los desafíos a la seguridad}

Como punto de partida es importante señalar que, a medida que el proceso de globalización ha avanzado, la concepción tradicional del Estado moderno se ha visto en buena medida alterada. Según Eissa (2005, p.3), dicho proceso ha producido al menos tres efectos en la noción de Estado: ha reducido la distancia económica; ha debilitado la soberanía (en sus diferentes dimensiones) y ha producido mayor incertidumbre e inestabilidad. En este contexto, si bien el Estado continúa siendo el actor principal en las relaciones internacionales, sus atributos, tales como la soberanía nacional, la seguridad nacional, el control legítimo de la violencia, el territorio y la población estable, se han puesto en riesgo.

Es así que en las últimas décadas, frente a los retos y desafíos que impone el proceso de globalización, y las implicancias que tienen fenómenos de naturaleza interméstica ${ }^{1}$, los Estados cada vez brindan mayor importancia a las dinámicas que se generan en el nivel local. Varios autores caracterizan lo local como ese espacio donde se articulan las distintas expresiones de

1 Término utilizado en el ámbito de las ciencias sociales para referirse a fenómenos con expresiones domésticas y ramificaciones internacionales. 
las contradicciones regionales y globales (López Ramírez, 2012, p. 186). Desde esa mirada, la localidad se define cada más en relación con lo global (Souza, 2004, citado en López Ramírez, 2012, p.186). A partir de esa mirada local-global, los Estados buscan dar respuestas a problemas tan complejos como los relativos a la seguridad pública.

Cabe señalar que la vulnerabilidad o resiliencia que pueda tener un Estado frente a fenómenos como el crimen y la violencia dependen de distintos factores, pero un factor clave es la forma en que el Estado resguarda su territorio y su capacidad para proveer de condiciones mínimas de orden público dentro de sus fronteras (Hurrell, 1998). Sobre el Estado y los niveles de estatalidad, en los últimos años han surgido una serie de categorías para analizar particularmente los problemas de crisis estatal, es decir, cuando el Estado deja de desempeñar ciertas funciones básicas weberianas. Sin embargo, escapa de los objetivos de este documento ahondar en esa discusión, más bien interesa analizar el objeto de estudio (rol de los CAM) desde la capacidad que tiene el Estado salvadoreño para controlar su territorio y penetrar en la sociedad a través de la prestación de servicios de seguridad pública².

Es a partir de esa lectura, y tomando como base los enfoques teóricos de la gobernabilidad, referida a la calidad del desempeño gubernamental (Camou citado en Morales Peña, 2012)—incluyendo a las municipalidades-, que se expondrá una serie de ideas orientadas a vislumbrar potenciales sinergias entre los CAM y la PNC para fortalecer la presencia y control del Estado en los territorios, lo cual pasa, entre otras dimensiones, por "hacer cumplir la ley sistemáticamente y la capacidad del Estado para proveer de condiciones mínimas de orden público dentro de sus fronteras" (Hurrell, 1998).

El Salvador de la posguerra atraviesa por un contexto difícil en términos de gobernabilidad, ello se expresa por los altos índices de violencia homicida que se registran en los últimos años ${ }^{3}$. Esa crisis de inseguridad tiene sus raíces en una serie de factores que ha estimulado y reproducido la delincuencia y la violencia en la sociedad salvadoreña. Entre esos se destacan los niveles históricos y acumulados de exclusión y vulnerabilidad social; los patrones culturales que toleran, normalizan y reproducen la

2 Para los propósitos de este análisis se entenderá la seguridad pública como un servicio a cargo del Estado que tiene como fines salvaguardar la integridad y derechos de las personas, así como preservar las libertades, el orden y la paz pública. En esa línea de análisis, Morales Peña (2011) plantea que "el desarrollo político de una sociedad no solamente radica en la fortaleza de sus instituciones, sino en cómo estas son capaces de gestionar los contextos de criminalidad e inseguridad".

3 Entre 2002 y 2012, la tasa de homicidios por 100000 habitantes alcanzó un promedio de 55.6. Para 2013, se registraron 2499 homicidios, es decir una tasa de 39.4 homicidios por 100000 habitantes. En 2014, la cantidad de homicidios aumentó registrándose 3912, lo cual representa una tasa de 61.1 homicidios por 100000 habitantes. Pero ha sido 2015 el año más sangriento en la historia de El Salvador de la posguerra. Cerró ese año con 6657 homicidios, promediando 18.2 personas asesinadas cada día (Smutt, 2013; Murcia, 2015; Valencia, 2016). 
violencia; y la débil presencia territorial de la institucionalidad del Estado (Consejo Nacional de Seguridad Ciudadana y Convivencia, 2015).

Esa ausencia del Estado en los territorios ha provocado que germinen "espacios de soberanía contestada" donde la autoridad del Estado, para todo efecto práctico, ha cesado de imperar y ha llegado a ser reemplazada por los mandatos impartidos por organizaciones criminales (Casas Zamora, 2012, p. 93), como son, en el caso de El Salvador, las pandillas o maras.

\subsection{La dimensión local en las estrategias de seguridad}

Para dar respuestas integrales a fenómenos complejos (multicausales), como son la violencia y la criminalidad, los Estados en los últimos años han privilegiado estrategias cada vez más integrales de seguridad. Estas no solo buscan dar respuesta a los problemas propios de la agenda de seguridad pública, sino también dan paso a una visión multidimensional para tratar tanto los problemas de convivencia ciudadana, como los factores que contribuyen a su reproducción social. Esa perspectiva sistémica de la gestión de la seguridad, a partir de la cual se actúa en diferentes planos, se complementa con otras estrategias que apuntan a la descentralización, desarrollo local, desarrollo territorial, que resultan útiles para asegurar la presencia integral del Estado en sus territorios.

De esta manera, cada vez es más clara la tendencia a la desconcentración y descentralización de las políticas de seguridad hacia los gobiernos locales, con el objetivo de responder con más eficiencia a las necesidades específicas de las urbes y de los territorios. Se habla de una territorialización de las políticas públicas, proceso que supone cierto grado de coordinación y articulación con el nivel central, transferencia de recursos y capacidades, junto con un marco normativo que otorgue las facultades necesarias a los gobiernos locales (Frühling, 2014).

Tomando en cuenta lo anterior, así como la visión integral en la que descansa la actual política de seguridad pública en El Salvador-donde la dimensión local se constituye en el pivote de las medidas impulsadas en materia de prevención de la violencia y el crimen-, se presta especial atención a las funciones que desempeñan los CAM en materia de prevención social del delito, entendiendo dichas políticas desde una lógica de participación de las comunidades y de las instituciones locales para el control social y la prevención situacional del delito (Dammert, 2003; Garrido, Farrington y Welsh, 2006). En tal sentido, para esta investigación ha sido de interés analizar el potencial rol de los CAM en las estrategias de recuperación territorial y seguridad definidas a un nivel central, o, en su defecto, vislumbrar sinergias y articulaciones entre estos y las instituciones del nivel central, particularmente la Policía Nacional Civil (PNC), para fortalecer el control social y del delito en los territorios. 
Si bien se reconocen algunas limitantes en este estudio-solo se hace referencia de manera general al marco jurídico, atribuciones y rol actual (y potencial) de estos cuerpos en un contexto de revalorización de lo local en los temas de seguridad pública—, se considera importante desarrollar análisis más específicos sobre temas de selección (perfiles), organización, formación, entrenamiento, armamento y logística, entre otras áreas estratégicas como las relacionadas con el control y supervisión, para tener una radiografía más completa de las capacidades de estas instancias. Así mismo, ello requerirá realizar análisis sobre el proceso de modernización y reformas que deben realizarse para que el Estado salvadoreño tenga capacidad para reinventarse y arraigarse en los territorios con políticas más amplias basadas en el desarrollo territorial, donde los gobiernos locales (y en consecuencia los CAM), por su proximidad, cumplen un papel fundamental para que el Estado recupere y asegure un control efectivo de los territorios.

\section{Reseña metodológica}

Para el presente estudio fueron retomadas las líneas metodológicas planteadas por Bravo y Marín González (2014) para investigaciones sociales sobre municipalismo, por lo que esta investigación es de carácter eminentemente cualitativo - con un importante soporte de información cuantitativa-. Su ruta metodológica se sustentó en la participación, la comunicación y la reflexión, privilegiando la profundidad sobre la extensión. Partió de las siguientes premisas epistemológicas: (1) carácter intersubjetivo de la realidad, en razón de lo cual cada localidad posee su propio referente de seguridad, de modo que para la descripción de sus lógicas de relación se requiere la participación activa de los principales actores locales; (2) interdisciplinariedad, para la aprehensión y comprensión de las propiedades y significados de la seguridad; y, (3) perspectiva de redes, para entender las dinámicas de interacción entre los actores clave del municipio.

El proceso de investigación se articuló en las siguientes etapas:

a. Teórico-documental. Para la construcción del marco teórico en que se sustentó la investigación. En algunos casos, incluso, una parte del marco teórico se elaboró a partir de los hallazgos obtenidos, como necesidad para dar explicaciones más completas y comparables a estos.

b. Constitucional-legal-institucional. Se analizaron los aspectos constitucionales, legales, jurisprudenciales y las ordenanzas municipales a fin de construir un mapa de las competencias, vacíos y relaciones institucionales. Asimismo, la capacidad instalada con la que cuentan los CAM (recursos, modalidades de entrenamiento, logística, armamento, tecnología, entre otros aspectos) para obtener una radiografía lo más completa posible sobre estos. 
c. Entrevistas semiestructuradas a actores clave: Concejales y exconcejales; exdirectores y directores de los CAM; miembros de la corporación policial, funcionarios y exfuncionarios del gabinete de seguridad pública y académicos expertos en estas áreas.

d. Análisis y recomendaciones. El análisis del papel de los CAM en la seguridad se realizó en función de las experiencias concretas de quienes han tenido a cargo funciones de seguridad pública y dirección de los CAM. Dicho análisis se concentró en tres sentidos: organizacionales, relacionales (municipio-PNC-comunidad), ordenamiento jurídico vigente, impedimentos, necesidades de reforma, etc. y recomendaciones estratégicas.

Los actores clave entrevistados fueron identificados y seleccionados con base en sus perfiles, tomando en cuenta su experiencia en roles de dirección, trabajo de campo o investigación, para que brindaran sus perspectivas, insumos e ideas concretas sobre la situación actual de los CAM de Santa Tecla y San Salvador, así como sobre el rol y perspectivas de estos en la seguridad pública. De igual manera se revisaron estrategias, planes y otros insumos que sirvieran como base para entender la relación entre el CAM y la PNC.

Se analizaron alrededor de diez perfiles de actores clave, de los cuales se seleccionaron finalmente cinco, con quienes se realizaron entrevistas a profundidad, semiestructuradas. Con ellos se abordó la dimensión institucional, jurídica, operativa, así como la visión de planificación y gestión territorial de la seguridad de los CAM.

\section{Tabla 1: Actores clave entrevistados}

\begin{tabular}{|c|c|c|c|}
\hline NOMBRE & INSTITUCIÓN & CARGOS OCUPADOS & FECHA \\
\hline Mauricio Arriaza Chicas & PNC & Comisionado, jefe de la Región Metropolitana & 22.10 .15 \\
\hline Gilbert Cáceres & CAM Santa Tecla & $\begin{array}{l}\text { Director del CAM de Santa Tecla y exdirector } \\
\text { del CAM de San Salvador }\end{array}$ & 27.10 .15 \\
\hline Julio Recinos & PNC & $\begin{array}{l}\text { Subinspector, de la Secretaría de Relaciones } \\
\text { con la Comunidad de la Dirección General } \\
\text { de la PNC }\end{array}$ & 18.11.15 \\
\hline Miguel Reyes & ANSP & $\begin{array}{l}\text { Encargado de formación de los CAM y } \\
\text { empresas de seguridad privada. }\end{array}$ & 20.11 .15 \\
\hline Eduardo Linares & MINGOB & $\begin{array}{l}\text { Exdirector del CAM de San Salvador, } \\
\text { exdirector OIE }\end{array}$ & 30.11 .15 \\
\hline
\end{tabular}

Fuente: Elaboración propia. 
El procesamiento de los insumos obtenidos se realizó a través de una matriz de vaciamiento, elaborada en función de los alcances y variables definidas para esta investigación, la cuales se encuentran desarrolladas en la tabla 2.

Tabla 2: Desarrollo de variables

\begin{tabular}{|c|c|c|c|}
\hline OBJETIVO & VARIABLE & INDICADORES & $\begin{array}{l}\text { INSTRUMENTOS } \\
\text { UTILIZADOS }\end{array}$ \\
\hline \multirow[t]{4}{*}{$\begin{array}{l}\text { 1. Analizar las } \\
\text { dimensiones legales } \\
\text { y funcionales que } \\
\text { rigen el desempeño } \\
\text { de los CAM. }\end{array}$} & \multirow[t]{4}{*}{$\begin{array}{l}\text { Idoneidad de los marcos } \\
\text { legales aplicables para } \\
\text { la función de los CAM } \\
\text { como agentes de } \\
\text { seguridad pública }\end{array}$} & $\begin{array}{l}\text { Coherencia/contradicciones } \\
\text { entre la Constitución y otros } \\
\text { instrumentos legales }\end{array}$ & $\begin{array}{l}\text { Exploración } \\
\text { y análisis legal } \\
\text { Entrevista } \\
\text { con actores clave }\end{array}$ \\
\hline & & $\begin{array}{l}\text { Existencia de normativa } \\
\text { secundaria sobre los CAM }\end{array}$ & $\begin{array}{l}\text { Exploración } \\
\text { y análisis legal }\end{array}$ \\
\hline & & $\begin{array}{l}\text { Ordenanzas municipales } \\
\text { que dan soporte a los CAM }\end{array}$ & $\begin{array}{l}\text { Exploración } \\
\text { y análisis legal }\end{array}$ \\
\hline & & $\begin{array}{l}\text { Atribuciones compartidas y } \\
\text { colisiones de competencias } \\
\text { entre los CAM y la PNC }\end{array}$ & $\begin{array}{l}\text { Exploración } \\
\text { y análisis legal } \\
\text { Entrevista } \\
\text { con actores clave } \\
\end{array}$ \\
\hline \multirow[t]{5}{*}{$\begin{array}{l}\text { 2. Evaluar la } \\
\text { capacidad } \\
\text { organizativa, el } \\
\text { despliegue y la } \\
\text { operatividad de los } \\
\text { CAM en los casos } \\
\text { estudiados }\end{array}$} & \multirow[t]{5}{*}{$\begin{array}{l}\text { Funcionamiento interno } \\
\text { delos CAM }\end{array}$} & $\begin{array}{l}\text { Entrenamiento y } \\
\text { capacitación }\end{array}$ & $\begin{array}{l}\text { Entrevista } \\
\text { con actores clave } \\
\text { Exploración } \\
\text { documental } \\
\text { Solicitud de acceso a } \\
\text { información pública }\end{array}$ \\
\hline & & Equipamiento y uniforme & $\begin{array}{l}\text { Entrevista } \\
\text { con actores clave } \\
\text { Exploración } \\
\text { documental } \\
\end{array}$ \\
\hline & & $\begin{array}{l}\text { Acceso y utilización } \\
\text { detecnología para su } \\
\text { funcionamiento }\end{array}$ & $\begin{array}{l}\text { Entrevista } \\
\text { con actores clave } \\
\text { Exploración } \\
\text { documental }\end{array}$ \\
\hline & & Salarios y jornadas de trabajo & $\begin{array}{l}\text { Entrevista } \\
\text { con actores clave } \\
\text { Exploración } \\
\text { documental } \\
\text { Solicitud de acceso a } \\
\text { información pública }\end{array}$ \\
\hline & & Eficiencia del organigrama & $\begin{array}{l}\text { Entrevista } \\
\text { con actores clave } \\
\text { Exploración } \\
\text { documental }\end{array}$ \\
\hline
\end{tabular}




\begin{tabular}{|c|c|c|c|}
\hline \multirow{4}{*}{$\begin{array}{l}\text { 3. Descripción de } \\
\text { la relación actual } \\
\text { de los CAM y la } \\
\text { PNCen el control } \\
\text { del territorio, el } \\
\text { combate y la } \\
\text { prevención de } \\
\text { la violencia y la } \\
\text { delincuencia, así } \\
\text { mismo, vislumbrar } \\
\text { potencialidadesde } \\
\text { mayor integración y } \\
\text { cooperación }\end{array}$} & \multirow[t]{4}{*}{$\begin{array}{l}\text { Situación actual de la } \\
\text { relación entre la PNC y } \\
\text { los CAM }\end{array}$} & $\begin{array}{l}\text { Planes y programas } \\
\text { conjuntos }\end{array}$ & $\begin{array}{l}\text { Entrevista con actores } \\
\text { clave } \\
\text { Exploración } \\
\text { documental }\end{array}$ \\
\hline & & $\begin{array}{l}\text { Conveniospara trabajo } \\
\text { conjunto }\end{array}$ & $\begin{array}{l}\text { Entrevista con actores } \\
\text { clave } \\
\text { Exploración } \\
\text { documental }\end{array}$ \\
\hline & & $\begin{array}{l}\text { Mesas o reuniones } \\
\text { periódicas de trabajo } \\
\text { conjunto }\end{array}$ & $\begin{array}{l}\text { Entrevista con actores } \\
\text { clave } \\
\text { Exploración } \\
\text { documental }\end{array}$ \\
\hline & & $\begin{array}{l}\text { Principales zonas o lugares } \\
\text { de actuación conjunta }\end{array}$ & $\begin{array}{l}\text { Entrevista con actores } \\
\text { clave } \\
\text { Exploración } \\
\text { documental }\end{array}$ \\
\hline \multirow[t]{5}{*}{$\begin{array}{l}\text { 4. Colegir rutas } \\
\text { potenciales para } \\
\text { generar sinergias } \\
\text { interinstitucionales } \\
\text { entre CAM y PNC } \\
\text { para el control del } \\
\text { delito }\end{array}$} & \multirow[t]{5}{*}{$\begin{array}{l}\text { Posibles rutas para el } \\
\text { aporte de los CAM en } \\
\text { áreas relacionadas con la } \\
\text { seguridad pública }\end{array}$} & $\begin{array}{l}\text { Reformas legales/ } \\
\text { constitucionales }\end{array}$ & $\begin{array}{l}\text { Entrevista con actores } \\
\text { clave } \\
\text { Exploración } \\
\text { documental } \\
\text { Análisis legal }\end{array}$ \\
\hline & & $\begin{array}{l}\text { Creación de nueva } \\
\text { legislación secundaria }\end{array}$ & $\begin{array}{l}\text { Entrevista con actores } \\
\text { clave } \\
\text { Exploración } \\
\text { documental } \\
\text { Análisis legal }\end{array}$ \\
\hline & & $\begin{array}{l}\text { Convenios } \\
\text { interinstitucionales para } \\
\text { formación y entrenamiento } \\
\text { de los CAM }\end{array}$ & $\begin{array}{l}\text { Entrevista con actores } \\
\text { clave } \\
\text { Exploración } \\
\text { documental }\end{array}$ \\
\hline & & $\begin{array}{l}\text { Convenios } \\
\text { interinstitucionales para } \\
\text { compartir información }\end{array}$ & $\begin{array}{l}\text { Entrevista con actores } \\
\text { clave } \\
\text { Exploración } \\
\text { documental }\end{array}$ \\
\hline & & $\begin{array}{l}\text { Recomendaciones para el } \\
\text { fortalecimiento institucional } \\
\text { de los CAM }\end{array}$ & $\begin{array}{l}\text { Entrevista con actores } \\
\text { clave } \\
\text { Exploración } \\
\text { documental }\end{array}$ \\
\hline
\end{tabular}

Fuente: Elaboración propia. 


\section{Marco jurídico aplicable}

Los antecedentes de la Policía Municipal en El Salvador datan de algunas décadas atrás. Algunos entrevistados identifican la existencia de cuerpos locales de seguridad desde el siglo XIX-conocidos como la descalza, los serenos, pasando por la Policía Municipal- hasta llegar a lo que en la actualidad se conoce como cuerpo de agentes municipales ${ }^{4}$. En sus orígenes la Policía Municipal protegía los bienes del municipio, y mantenía el orden en las calles y avenidas de la ciudad. Dentro de sus principales labores, estaba retirar personas ebrias que quedaban en las calles y que ocasionaban una mala impresión de la ciudad; sus agentes eran conocidos como "choriceros" por desarrollar prácticas de matanzas de perros callejeros dándoles chorizos envenenados para eliminarlos (Portillo Chinchilla, 1998).

Los firmantes de los Acuerdos de Paz de 1992 coincidieron en reformar la Constitución de la República de 1983 para concentrar las tareas de seguridad pública en la naciente institución de la Policía Nacional Civil. Buscaban así dejar atrás los antiguos cuerpos policiales y avanzar hacia una policía más profesional, respetuosa de los derechos humanos y menos sujeta a los vaivenes políticos. En tal sentido, los firmantes de los Acuerdos de Paz buscaron que el término "policía"quedara reservado y restringido para la naciente PNC, así como también reservar para esta institución las competencias de seguridad pública ${ }^{5}$.

Sin embargo, más allá de la intención y fundamento político para reservar el término "policía" para la PNC, lo cierto es que el Código Municipal (CM) no fue reformado en tal sentido. En sus artículos 4 y 48 establece claramente que corresponde al alcalde organizar y dirigir la Policía Municipal, dando claramente la competencia a los municipios de prestar dicho servicio.

Con respecto a la reserva constitucional de las funciones de seguridad pública para la PNC, es importante mencionar en el 2011 se aprobó la Ley Marco para la Convivencia Ciudadana y Contravenciones Administrativas, con el objetivo de establecer normas de convivencia que conlleven a la promoción y preservación de la seguridad ciudadana, y a la prevención de la violencia social; además, se dio competencia para su aplicación a los

4 La Policía Municipal de la ciudad de San Salvador fue fundada en el año de 1886 bajo la administración de don Federico Prado. El marco jurídico de este cuerpo policial se basaba en la Ley de la Policía (decreto legislativo del 12 de mayo de 1895). Fue durante la gestión municipal del doctor Héctor Silva Argüello que, en el municipio de San Salvador, se tomó la decisión de cambiar las funciones y atribuciones de este cuerpo, las cuales entraban en contradicción con la recién creada PNC, dando vida al ahora conocido como Cuerpo de Agentes Metropolitanos.

5 El punto trascendental de los Acuerdos de Paz radicó en la reformulación de la misión de la Fuerza Armada a cambio de la desmovilización de la guerrilla del FMLN. Esto suponía, entre otros cambios, reducir el tamaño del Ejército, supeditarlo al poder civil, así como fortalecer y reorganizar las dependencias policiales. 
concejos municipales y a los CAM. Esta ley delimita y enmarca de manera adecuada las funciones reservadas para los CAM en áreas relacionadas con la seguridad ciudadana, tal como la denomina la ley, abriendo así una ventana legal para la colaboración del CAM con la PNC en tareas de prevención y control social, sin menoscabar la reserva constitucional del artículo 159.

Los cuerpos legales, así como los documentos de política institucional y política pública que fueron analizados se listan en la tabla 3.

\section{Tabla3: Legislación y documentos políticos analizados}

\begin{tabular}{|c|c|}
\hline $\begin{array}{l}\text { Legislación y } \\
\text { documentos }\end{array}$ & \\
\hline $\begin{array}{l}\text { Constitución } \\
\text { de la República }\end{array}$ & Arts. 202-207; art. 159.D.O. 234 (281) \\
\hline \multirow[t]{9}{*}{ Leyes secundarias } & Código Municipal.D.O. 23 (290). \\
\hline & $\begin{array}{l}\text { Ley Marco para la Convivencia Ciudadana y Contravenciones Administrativas. D.O. } 80 \\
\text { (391). }\end{array}$ \\
\hline & Ley orgánica de la Policía Nacional Civil de El Salvador. D.O. 144 (316). \\
\hline & Ley de los Servicios Privados de Seguridad. D.O. 18 (350). \\
\hline & Ley Orgánica de la Academia Nacional de SeguridadPública. D.0. 42 (314). \\
\hline & $\begin{array}{l}\text { Ley de los Servicios de Seguridad del Estado, Instituciones Autónomas y de las } \\
\text { Municipalidades. D.O. } 18 \text { (350). }\end{array}$ \\
\hline & $\begin{array}{l}\text { Ley de Creación del Fondo para el Desarrollo Económico y Social de los Municipios. D.O. } \\
42 \text { (342). }\end{array}$ \\
\hline & Ley Orgánica del Instituto Salvadoreño de Desarrollo Municipal. D.O. 52 (294). \\
\hline & Ley general Tributaria Municipal. D.0. 242 (313). \\
\hline \multirow{2}{*}{$\begin{array}{l}\text { Documentos } \\
\text { políticos }\end{array}$} & Acuerdos de Paz de 1992. \\
\hline & Directrices y Manual de formación de policía comunitaria de El Salvador. \\
\hline \multirow{2}{*}{$\begin{array}{l}\text { Ordenanzas } \\
\text { municipales }\end{array}$} & Ordenanza para la Convivencia Ciudadana del Municipio de San Salvador. \\
\hline & $\begin{array}{l}\text { Ordenanza de Convivencia Ciudadana y Contravenciones Administrativas del } \\
\text { Municipio de Santa Tecla }\end{array}$ \\
\hline
\end{tabular}

*D. O. significa Diario Oficial.

Fuente: Elaboración propia. 


\subsection{Leyes y reglamentos}

En la actualidad, el régimen legal-municipal vigente en El Salvador está constituido principalmente por la Constitución de 1983 y por el Código Municipal de 1986. A esto debe agregarse un conjunto de leyes sectoriales y reglamentos de las mismas, así como otra legislación relacionada. En los últimos años, el régimen local salvadoreño ha sufrido los siguientes cambios: (1) reformas a la Ley del FODES, (2) reformas a la ley del FISDL; (3) la formulación de la Estrategia Nacional de Desarrollo Local (ENDL); y (4) reformas a las competencias municipales en el Código Municipal. También se han acumulado propuestas de reformas directas al Código Municipal (Córdova y Seligson, 2001).

La Constitución de la República establece las funciones y competencias en los artículos comprendidos del 202 al 207, abriendo la posibilidad de que estas se desarrollen en unas leyes secundarias. Por su parte, la Constitución en su artículo 159 establece que la función de seguridad pública le corresponderá exclusivamente a la Policía Nacional Civil (PNC). Este artículo proviene de una reforma constitucional fruto de los Acuerdos de Paz en la década de los noventa.

En materia municipal, para 1998, ya se señalaba "la existencia de un marco legal relacionado con las municipalidades, plagado de ambigüedades, vacíos y contradicciones" (FUNDE y FUNDAUNGO, 1998, p. 37). Más de quince años después, dicha dispersión continúa presente y también afecta directamente sobre el funcionamiento y las competencias de los denominados cuerpos de agentes municipales ${ }^{6}$. La dispersión es tal que en algunos cuerpos legales, como la Ley Marco para la Convivencia Ciudadana y de Contravenciones Municipales ${ }^{7}$, se les denomina como cuerpos de agentes municipales, mientras que en otros, como el Código Municipal, aún les denomina como policías municipales, dejando en evidencia la falta de sintonía. En tal sentido, uno de los primeros retos a nivel jurídico relativo a los CAM es buscar la uniformidad de los términos.

Por su parte la ley contravencional ${ }^{8}$, que data de 2011, establece com. petencias en materia de seguridad para los CAM. En su artículo 28 les da potestad para actuar ante una serie de faltas que clasifica así: a) las

6 Mediante acuerdo municipal n. ${ }^{\circ} 4$ (6 de junio de 1995), el concejo municipal de San Salvador decidió ustituir el nombre de la Policía Municipal por el de Cuerpo de Agentes Metropolitanos. Es importante mencionar que para los municipios de Santa Tecla como de San Salvador, las siglas CAM significan Cuerpo de Agentes Metropolitanos, mientras que para el resto de municipios y acorde con la Ley de Contravenciones se conocen como cuerpos de agentes municipales, bajo las mismas siglas, CAM.

7 También conocida como Ley de Contravenciones o Contravencional, denominándosele de esa manera en este artículo para abreviarla.

8 Esta leyderoga la antigua Ley de Policía, emitida mediante decreto ejecutivo s/n, (21 de febrero de 1879), publicado en el Diario Oficial154, tomo 49, del 2 de julio de 1900; así como, sus posteriores reformas y todas aquellas leyes, decretos y disposiciones sobre la materia, en todo lo que contraríe el texto y los principios que contiene la Ley de Contravenciones. 
relativas al debido comportamiento en lugares públicos; b) las relativas a la tranquilidad ciudadana; c) las relativas al medio ambiente y d) las relativas a la tenencia de animales; dichas faltas pueden ser sancionadas con amonestación verbal, reparación de los daños, decomisos, trabajo de utilidad, multas, suspensiones de permisos y licencias, y cierre definitivo. La misma ley establece la obligación para las municipalidades de crear ordenanzas municipales que regulen la convivencia ciudadana a fin de evitar conflictos comunitarios que ocasionen mucha violencia.

Entre las responsabilidades y funciones que la ley contravencional asigna a los CAM, referidas de forma directa e indirecta a temas de seguridad pública, se encuentran las siguientes: velar por el bien común y la armónica convivencia ciudadana; iniciar la investigación de las contravenciones establecidas en dicha ley, cuando se presentare aviso o denuncia, verbal o escrita, por parte de algún ciudadano o se tuviere noticia por cualquier medio; remitir inmediatamente a la PNC a todos aquellos ciudadanos que sean sorprendidos en flagrancia en la comisión de un hecho delictivo; intervenir en todo hecho que conlleve perjuicio hacia los bienes públicos; participar, dentro de sus facultades, en los planes de prevención de la violencia del municipio; y, resguardar y asegurar la tranquilidad pública, en coordinación con la PNC.

Por su parte, según el artículo 13 de la referida ley, entre las responsabilidades asignadas a la PNC estánimpulsar y participar con los concejos municipales, comités, mesas interinstitucionales, sociales y otras organizaciones que contribuyan a la prevención de la violencia y a la convivencia ciudadana.

\subsection{Ordenanzas y acuerdos municipales}

En complemento del marco normativo en materia de seguridad ciudadana ${ }^{9}$, el gobierno municipal de San Salvador estableció en noviembre de 2011 , la Política Municipal de Convivencia, Mediación y Seguridad Ciudadana con el objeto de generar condiciones que contribuyeran a mejorar las condiciones de los habitantes del municipio en los aspectos que señala dicha política. Asimismo, en 2012 el municipio de San Salvador aprobó la Ordenanza para la Convivencia Ciudadana para velar por el orden, el bien común y la convivencia armónica del municipio. Según el artículo 2 de dicha ordenanza, la finalidad de la misma es educar a la población en la prevención de conductas nocivas a la ciudadanía, fomentando una cultura de respeto. A partir de ese marco normativo, algunos sostienen que "las

9 Es importante remarcar la distinción terminológica en estos cuerpos normativos municipales, pues hablan de seguridad ciudadana, no de seguridad pública. Cambio que no solamente responde a un probable paradigma distinto, sino también permite que los municipios incursionen en aspectos relativos a la seguridad. Como se mencionó anteriormente, la Constitución luego de los Acuerdos de Paz de 1992 estableció que la Seguridad Pública estaría a cargo solamente de la Policía Nacional Civil. 
municipalidades cuentan con todas las condiciones para contribuir en dar tratamientos relacionados a prevención primaria del delito" (Gilbert Cáceres, entrevista, Santa Tecla, 27 de octubre de 2015).

Si bien las facultades y funciones de los CAM, a lo largo de los años se han concentrado principalmente en la protección del patrimonio municipal y en velar por el cumplimiento de las ordenanzas municipales, tal como se refleja en la tabla 4, estos cuerpos también han coadyuvado en los esfuerzos de seguridad pública, a partir de leyes secundarias, ordenanzas municipales y otros acuerdos de carácter local, así como por lo que establecen las estrategias de seguridad diseñadas desde el Ejecutivo.

Al revisar las experiencias del CAM de San Salvador y de Santa Tecla sobresale que dichos cuerpos desempeñan diferentes funciones en materia de prevención, seguridad y convivencia ciudadana. Así lo expresa en su sitio web la Alcaldía de San Salvador, al definir al CAM como "un cuerpo de agentes municipales comunitario, jerarquizado y disciplinado, encargado de articular la atención ciudadana con el cumplimiento de la normativa municipal, velando por la limpieza, orden y seguridad de los espacios públicos, el patrimonio municipal y la ciudadanía en general, contribuyendo a la prevención y disuasión del delito, y la tranquilidad ciudadana".

En el caso del CAM de Santa Tecla, la ordenanza reguladora del servicio de dicho cuerpo -aprobada mediante decreto n. ${ }^{\circ} 5$, de noviembre de 2015- establece que el CAM actuará de conformidad a la doctrina policial en atención al servicio ciudadano, garantizando el cumplimiento de la normativa municipal y demás leyes afines, incidiendo en la resolución de los problemas de la comunidad. Asimismo, establece que el CAM participará en la prevención social de la violencia, acompañando diversos programas preventivos, promoviendo la armonía social, la convivencia, la tranquilidad y seguridad ciudadana.

Si bien no existe un claro marco normativo que defina el rol de los CAM en apoyo a la seguridad pública y concretamente en su colaboración con la PNC, en la práctica sus funciones se concentran en la prevención y convivencia ciudadana, y se desarrollan en función del liderazgo que imprima el concejo municipal de turno a través del director del $\mathrm{CAM}^{10}$, así como con base en el Código Municipal, la Ley Marco para la Convivencia Ciudadana y Contravenciones Administrativas de 2011 y otras ordenanzas administrativas aprobadas por los concejos municipales.

10 En cuanto a la estructura organizativa de los CAM, tanto para el de San Salvador y como para el de Santa Tecla, su máxima autoridad es el alcalde. Si bien el CAM de San Salvador depende de los lineamientos de su director, opera en estrecha relación con la Subdirección y mantiene constante coordinación con laDelegación Contravencional, la Gerencia Legal y la Unidad de Convivencia, Mediación y Seguridad Ciudadana de la municipalidad. Por su parte, en el CAM de Santa Tecla, el director es la autoridaddelegada por el alcalde para la coordinación general, administrativa y operativa del mismo, siendo asistido por los subdirectores que de acuerdo a la necesidad del servicio se requieran. 


\section{La gestión local de la seguridad pública: el rol del CAM}

\subsection{Prevención}

Desde finales de los noventa y principios del siglo XXI, fue ganando terreno en los debates públicos sobre seguridad pública, la necesidad de incluir a las municipalidades, en el marco de enfoques más integrales, particularmente en lo que se refiere a las políticas de prevención de la violencia y del crimen. Uno de esos primeros impulsos se dio en 1997 cuando la Alcaldía de San Salvador diseñó un plan de gobierno para lograr la participación de diferentes actores en el proceso de transformación y conversión de la capital en una ciudad segura. A partir de esos años, al igual que San Salvador, otras alcaldías promulgaron ordenanzas de participación ciudadana y crearon estructuras, con personal propio, encargadas de impulsar programas que fueran más allá de la tradicional oferta municipal de limpieza, ornato, iluminación y mercados (Arévalo Herrera, 2009).

Ese fue el caso de Santa Tecla que, pese a ser uno de los municipios más afectados por los terremotos del 2001, con el paso de unos años se constituyó como un modelo en la gestión del desarrollo local y seguridad ciudadana. A partir del 2002 su concejo municipal elaboró su planeación estratégica para diez años e incorporó como parte de las mesas de trabajo el componente de seguridad y convivencia ciudadana. Desde ese momento, la prevención y la reducción de la violencia fueron un reto asumido por la municipalidad. Para 2004 se inició la fase de diagnóstico que sirvió como base para la formulación de la primera Política Municipal de Prevención y Seguridad Ciudadana en $2005^{11}$, basada en la prevención, la articulación interinstitucional y la participación ciudadana.

Para el año 2006 fue instalado un Observatorio de la violencia y el delito, que monitorea el comportamiento del delito a través de mapas georeferenciados donde se manifiestan los hechos delictivos, lo cual permite identificar los factores que inciden en la violencia y la criminalidad para proponer medidas para la prevención y disminución de los mismos. En 2008, secreó el Concejo Interinstitucional para la Prevención de la Violencia'2, el Concejo Ciudadano para el Desarrollo Local y los Comités de Diálogo para la Convivencia, instancias que prepararon el terreno para acercar a

11 En ese mismo año se asignó un 14\% del presupuesto municipal para financiar los programas de convivencia y prevención de la violencia (AMUPREV,s.f.).

12 Como parte de las instituciones que conforman este comité se encuentran la PNC, el Consejo Ciudadano de Desarrollo Local, Cuerpo de Agentes Metropolitanos, la Fiscalía General de la República, la Procuraduría para la Defensa de los Derechos Humanos, Procuraduría General de la República, el Instituto de Medicina Legal, la Academia Nacional de Seguridad Pública, el Ministerio de Educación, el Instituto Nacional de la Juventud, la Dirección General de Prevención Social de la Violencia y Cultura de Paz del Ministerio de Justicia y Seguridad Pública, ONG que operan en el municipio y representantes de las iglesias católicas y evangélicas. 
la municipalidad a las comunidades, en especial aquellas que durante décadas habían estado sin presencia del gobierno local (INTERPEACE, 2014). En unos años, Santa Tecla ganó una especie de reconocimiento por la recuperación y creación de espacios públicos tales como el Paseo El Carmen, el estadio Las Delicias, la recuperación del Palacio Municipal, así como los circuitos culturales y de parques municipales, a través de acciones articuladas y coordinadas entre la municipalidad, las instituciones del gobierno central, el sector privado y las comunidades ${ }^{13}$.

A nivel nacional, con la llegada al Ejecutivo del gobierno de Mauricio Funes en 2009 cobra mayor fuerza en la agenda de la seguridad pública la apuesta por los temas de prevención desde lo local. Según la Estrategia Nacional de Prevención de la Violencia (Gobierno de El Salvador, 2012), el municipio pasa a ser el espacio más próximo donde se expresan los problemas y confluyen e interactúan todos los actores que deben participar en la prevención de la violencia. Desde ese enfoque se busca intervenir en los factores subyacentes del fenómeno de la violencia, colocando al municipio como su principal pivote; ello significa desplegar procesos que generen la suficiente capacidad técnica, programática y financiera para responder a las necesidades concretas y específicas de cada territorio, articulando de manera coherente y eficiente los diferentes niveles de gobierno (nacional, departamental y municipal) y propiciando altos niveles de participación de los actores de la sociedad, como sujetos de las transformaciones y el abordaje de las dinámicas que generan violencia y delincuencia.

Para operativizar dicha estrategia se debe desarrollar un trabajo trans. versal con instituciones pertenecientes a los gobiernos central y local, y a la sociedad civil; por otra parte, se trata de un enfoque intersectorial que involucra a diversas áreas como salud, educación, desarrollo social, comunitario, local e infanto-juvenil, entre otras. Para ello, se han puesto en funcionamiento los comités municipales de Prevención de la Violencia, instancias responsables de conducir la política de prevención de la violencia y del delito en el municipio, y la coordinación interinstitucional entre el sector de justicia y seguridad, instituciones del gobierno central y actores locales. Desde estas instancias se elaboran diagnósticos y planes de prevención de la violencia ${ }^{14}$. En ese sentido, gradualmente se ha ido dando paso a una nueva forma de trabajo en los territorios para implementar estrategias integrales y participativas para tratar la violencia y la inseguridad.

13 Entre otras acciones, en junio de 2013, el Concejo Municipal aprobó la Ordenanza para la Prevención de la Trata de Personas en este municipio con el propósito de prevenir, reprimir y sancionar cualquier actividad de explotación principalmente hacia mujeres, niñas, niños y jóvenes.

14 Entre los actores que integran dichos comités figuran el alcalde o alcaldesa, concejales municipales, el responsable de la instancia de promoción social del gobierno municipal, el jefe del cuerpo de agentes municipales (CAM), iglesias, entre otros. 
A fin de fortalecer las capacidades de la gestión local de la seguridad, los gobiernos municipales han ido adaptando su institucionalidad en función del cambio de paradigma. En el caso de San Salvador, en los últimos años se han promovido una serie de medidas en materia de seguridad ciudadana, convivencia y prevención de la violencia, contando con instrumentos como la Política Municipal de Convivencia, Mediación y Seguridad Ciudadana (Alcaldía Municipal de San Salvador, 2011); el Programa Municipal de Prevención de la Violencia, y la Ordenanza para la Convivencia Ciudadana del Municipio de San Salvador. Asimismo, esta alcaldía cuenta con un Observatorio Municipal que ofrece estadísticas referidas a delitos de violencia intrafamiliar, robo, hurtos, homicidios, lesiones, faltas contravencionales, entre otros. La fuente principal del que se alimenta dicho mecanismo es el Comité de Seguridad Ciudadana, conformado por representantes de la PNC, Fuerza Armada, Fiscalía General de la República y el CAM, coordinado por la Comisión de Convivencia, Mediación y Seguridad Ciudadana de la municipalidad de San Salvador.

Este tipo de acciones que privilegian la gestión local de la seguridad a través de mecanismos de coordinación interinstitucional muestran, en buena medida, el peso que se le otorga en las políticas de seguridad pública a los gobiernos locales, particularmente en temas prevención, ya que son las autoridades locales, en representación del Estado, quienes en un primer momento deben dar respuesta a las problemáticas que afectan la convivencia y seguridad de los ciudadanos (Acero Velásquez, s. f., p. 177). 


\section{Tabla 4: Principales funciones de los cuerpos de agentes municipales (San Salvador/Santa Tecla)}

\begin{tabular}{|c|c|}
\hline CAM San Salvador & CAM Santa Tecla \\
\hline $\begin{array}{l}\text { Vigilar, custodiar, inspeccionar el patrimonio } \\
\text { municipal, tales como: edificios y oficinas } \\
\text { municipales, mercados, cementerios, zonas verdes, } \\
\text { parques, centros de recreación, teatros y otros } \\
\text { bienes públicos. }\end{array}$ & $\begin{array}{l}\text { Resguardar el patrimonio municipal: edificios } \\
\text { municipales, oficinas, mercados, cementerios, } \\
\text { anfiteatros, etc. }\end{array}$ \\
\hline $\begin{array}{l}\text { Cumplir y hacer cumplir las leyes, ordenanzas, } \\
\text { reglamentos y acuerdos con base en las } \\
\text { atribuciones del municipio, art. } 4 \text {. Código } \\
\text { Municipal, siempre y cuando no contraríen lo } \\
\text { establecido en otras leyes. }\end{array}$ & $\begin{array}{l}\text { Cumplir y hacer cumplir las leyes, ordenanzas, } \\
\text { reglamentos, decretos y acuerdos del concejo } \\
\text { municipal para mejorar la convivencia, el orden y } \\
\text { seguridad ciudadana. } \\
\text { Brindar la prestación de seguridad preventiva a } \\
\text { la ciudadanía en espectáculos, manifestaciones } \\
\text { públicas y otros eventos. }\end{array}$ \\
\hline $\begin{array}{l}\text { Contribuir al buen funcionamiento de transporte } \\
\text { local, las terminales de transporte de pasajeros, } \\
\text { y los lugares de carga, siempre y cuando no } \\
\text { transgreda otras leyes que regulen la misma } \\
\text { materia. }\end{array}$ & $\begin{array}{l}\text { Coadyuvar al esfuerzo de mantener los espacios } \\
\text { públicos libres de obstáculos para el tránsito } \\
\text { vehicular y peatonal, de conformidad con lo } \\
\text { establecido en las ordenanzas municipales; } \\
\text { ordenar los espacios de comercio informal y } \\
\text { colaborar de manera coordinada con las instancias } \\
\text { correspondientes en el ordenamiento, la seguridad } \\
\text { y la prevención vial. }\end{array}$ \\
\hline $\begin{array}{l}\text { Prestar auxilio a la ciudadanía en casos de } \\
\text { accidente, catástrofe y calamidad pública. }\end{array}$ & $\begin{array}{l}\text { Prestar auxilio a la ciudadanía en coordinación } \\
\text { con las diferentes instituciones de servicio a la } \\
\text { comunidad, sean estas gubernamentales o no. }\end{array}$ \\
\hline $\begin{array}{l}\text { Informar en el término de ley a la Policía Nacional } \\
\text { Civil o Fiscalía General de la República, según sea el } \\
\text { caso, si al llevar a cabo una inspección se constate } \\
\text { que existe prostitución o se estuviera cometiendo } \\
\text { cualquier otro delito. }\end{array}$ & $\begin{array}{l}\text { Mantener una comunicación y coordinación } \\
\text { permanente con la PNC, instituciones civiles y } \\
\text { militares, para la elaboración y ejecución de planes } \\
\text { de convivencia y seguridad ciudadana para la } \\
\text { prevención de la violencia. }\end{array}$ \\
\hline $\begin{array}{l}\text { Llevar a cabo inspecciones en establecimientos } \\
\text { y negocios, a fin de determinar la actividad que } \\
\text { realizan. }\end{array}$ & $\begin{array}{l}\text { Colaborar con la organización social o comunal } \\
\text { con el propósito de crear condiciones de } \\
\text { participación y/o convivencia ciudadana. }\end{array}$ \\
\hline
\end{tabular}

Fuente: Elaboración propia (Alcaldía Municipal de San Salvador, 1999; Alcaldía Municipal de Santa Tecla, 2015). 
De manera general, en los últimos años, la coordinación entre CAM y PNC ha tomado forma en el trabajo que realizan los CAM para dar cumplimiento a ciertas ordenanzas y reglamentos municipales, como son aquellas relativas al resguardo y protección del patrimonio municipal, inspecciones a establecimientos comerciales y en algunos espacios públicos como parques y plazas, asimismo se han establecido ordenanzas en temas relacionados a la seguridad como son aquellas relacionadas a la portación de armas de fuego. Estas últimas son claro ejemplo del rol que realizan los CAM en materia de prevención del delito y la violencia, ya que, si un agente municipal se percata de que una persona porta un arma de fuego en un lugar prohibido, de inmediato debe reportarlo a las autoridades de la PNC.

Entre otras de las funciones que desempeñan estos cuerpos, está el servicio de seguridad en mercados, espacios públicos, así como en eventos multitudinarios de carácter deportivo, conciertos, ferias, entre otros. En estas funciones, si bien los CAM planifican sus propias acciones según las atribuciones que les corresponden, su sola presencia constituye un factor disuasivo pero principalmente preventivo, que apoya el trabajo de control y prevención que realiza la PNC.

En Santa Tecla, con la aprobación de la Ordenanza para la Prevención de la Trata de Personas en 2013, se le asignan algunas atribuciones al CAM entre las que se destacan: "velar que en el espacio público y en establecimientos privados de acceso público no se generen ambientes que sean propicios para la comisión del delito (...), retener y remitir de forma inmediata a la Policía Nacional Civil y/o a la Fiscalía General de la República, a quien sea sorprendido en flagrancia en la comisión del delito de trata de personas" (Alcaldía de Santa Tecla, 2013).

Los diferentes instrumentos normativos apuntan a un trabajo coordinado entre CAM y la PNC, el cual se evidencia en la práctica en los esfuerzos que realizan las alcaldías por ordenar sus centros históricos. En casos como el de San Salvador (centro), las aceras han dejado de cumplir su función natural y han pasado a ser corredores de comercio informal. En esos esfuerzos por ordenar los centros históricos y recuperar espacios públicos, los CAM cumplen un papel activo. Un ejemplo de ello sucedió en noviembre de 2015, cuando el CAM de Santa Tecla, en coordinación con la PNC, desalojó a alrededor de 200 vendedores informales ubicados en los alrededores de los parques San Martín y Daniel Hernández ubicados en el centro histórico de esta ciudad. Según señaló, en su momento, el alcalde de dicho municipio, el desalojo tomó como base el artículo 4, numerales 3, 23 y 25, del Código Municipal; así como el artículo 56 de la Ordenanza de Convivencia Ciudadana y Contravenciones Administrativas; y el artículo 16 de la Ordenanza de Ornato, Nomenclatura y Rótulos de dicha municipalidad. 
Por otra parte, la colaboración entre ambas instituciones se expresa también en los patrullajes conjuntos que realizan elementos del CAM con agentes de la PNC. En Santa Tecla, ese tipo de patrullajes se realiza desde 2006 para prevenir actos delictivos. En San Salvador, este tipo de patrullajes se registran desde 2007 para brindar seguridad en parques y plazas, así como en respuesta a la invasión de espacios públicos y aceras por parte del sector informal. Para festividades de semana santa y otras fechas importantes, en el marco de los planes de seguridad que elabora la PNC, los agentes del CAM cumplen con la función de brindar seguridad preventiva a través de los patrullajes conjuntos que realiza junto a la PNC.

Otra función importante y clave para el trabajo que la PNC realiza son las inspecciones que realizan los CAM a los establecimientos comerciales para verificar que cumplan con lo que establecen las diferentes ordenanzas municipales aplicables a cada municipio. Las regulaciones van desde la verificación de permisos para operar, impuestos municipales, regulación de ventas de bebidas alcohólicas, así como identificación de lugares de tolerancia.

En líneas generales esas son algunas de las principales funciones que realizan los CAM relacionadas con los temas de seguridad pública. Vistas desde un enfoque integral de la seguridad, este tipo de funciones resultan complementarias a las actividades que realiza la PNC en materia de control, represión y prevención del delito.

La coordinación entre los CAM y la PNC también se ha expresado en los esfuerzos que realizan las alcaldías por modernizar sus sistemas de información y estadísticas en materia de seguridad. Además de los observatorios municipales de prevención de la violencia se han puesto en funcionamiento sistemas de video-vigilancia para asegurar un mayor control de las zonas. Por ejemplo, en años recientes, se ha implementado en Santa Tecla, el Proyecto de Seguridad Inalámbrica, facilitado a través de un asocio público-privado y la cooperación de USAID, dirigido a fortalecer a la PNC y el CAM en el monitoreo y análisis de los patrones del crimen en tiempo real. Este proyecto usa la tecnología para recolectar y compartir información, y así contar con un mapeo y análisis del delito lo más detallado posible ${ }^{15}$ para actuar y prevenir.

En el caso de San Salvador, la alcaldía trabaja en el proyecto de instalación de alrededor de 123 cámaras de video-vigilancia en lugares estratégicos de la capital, las cuales serán interconectadas para que sean monitoreadas por personal especialista del Sistema de Emergencias 911.

15 La segunda etapa de este proyecto, además de continuar ejecutándose en Santa Tecla, se ampliará a otros municipios del Área Metropolitana de San Salvador, incluyendo Antiguo Cuscatlán, San Martín, San Salvador, Apopa, Ciudad Delgado y Ayutuxtepeque. 


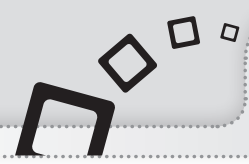

\section{Figura 1: Observatorio Municipal de Santa Tecla}

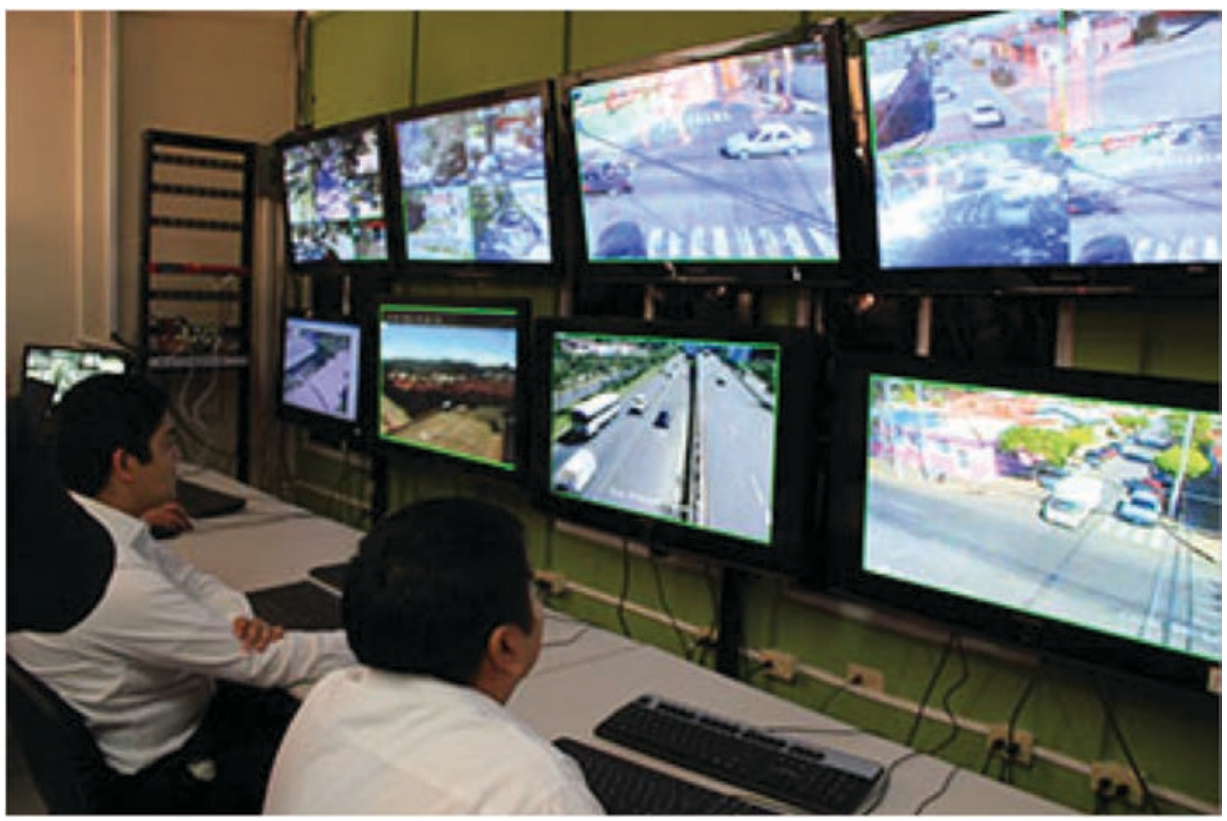

Fuente: AMUPREV, s.f.

Asimismo, en los casos analizados se han realizado algunas inversiones dirigidas a modernizar, a través de tecnología, la gestión local de la seguridad. En esa línea, la alcaldía de Santa Tecla ha desarrollado una aplicación para teléfonos inteligentes llamada Tecla App, para que los habitantes de ese municipio denuncien asaltos, robos, hurtos, violencia intrafamiliar, entre otros. Esto permite - a través de un trabajo coordinado entre 911 de la PNC, Fiscalía General de la República (FGR) y el CAMreaccionar inmediatamente para enviar un patrullaje preventivo o grupo de reacción conjunto de CAM y PNC (Taura, 2015).

\subsection{Los CAM en la implementación del nuevo modelo policial basado en la filosofía de policía comunitaria}

Desde su creación y como parte de su razón de ser, la PNC se inclinaría por construir un modelo policial cercano a la sociedad. No obstante, por diversas razones propias de su proceso histórico como institución y por la falta de claridad estratégica del Estado salvadoreño frente a los desafíos de la seguridad pública, esta institución fue perdiendo su norte y construyendo su identidad en función de las coyunturas del momento. 
Ahora bien, en los últimos años, con el propósito de dotar de una identidad formal a la PNC y fortalecer el servicio policial, se han realizado esfuerzos para recuperar el enfoque de trabajo comunitario y de servicio a la comunidad. Este fue uno de los pilares fundamentales de la reforma policial emanada de los Acuerdos de Paz (IUDOP, 2014, p. 78), a través de la apuesta por establecer un nuevo modelo policial basado en la Filosofía de Policía Comunitaria (FPC) ${ }^{16}$.

Tras las experiencias piloto desarrollas en La Unión y Colón (entre los años 2008-2009), la PNC ha avanzado en sentar las bases normativas y operativas que guían la implementación de este nuevo modelo policial, particularmente a partir de 2010 con la elaboración de la doctrina institucional y el plan que establecen el marco referencial para la implementación de la FPC. En un inicio, dicho esfuerzo — según la primera orden de operaciones para la implementación de la FPC - se concentró en 26 subdelegaciones policiales a nivel nacional, tomando como base los diferentes instrumentos diseñados para asegurar una efectiva puesta en práctica de esta nueva forma de trabajo en los territorios. A partir de esa primera orden de operaciones, cada subdelegación trabajaría en función de las cinco fases definidas para la implementación de la FPC ${ }^{17}$.

Posteriormente, en julio de 2014 se aprueba la segunda orden de operaciones para asegurar la implementación de la FPC a nivel nacional. Este nuevo modelo policial, tal como lo establece su plan de implementación, demanda que el personal policial, en todos sus niveles, trabaje en función de un modelo proactivo más que reactivo de la mano con los diferentes actores sociales en los territorios. A través de la FPC se busca fortalecer los mecanismos de asociación y cooperación con gobiernos municipales, consejos municipales de prevención de la violencia, y otras instancias como los Consejos Departamentales de Alcaldes, la Corporación de Municipalidades (COMURES) y otros actores como la empresa privada.

En el marco del proceso de implementación de la FPC, la PNC ha avanzado en la sectorización y subsectorización de zonas de patrullaje a partir de las cuales se realiza el despliegue policial comunitario y se asigna un agente policial responsable (del subsector) para desarrollar trabajo comunitario. A partir de esa distribución, la PNC —con base a diagnósticos propios y con participación de actores locales (como son los CAM) ${ }^{18}$ - formula

16 Para viabilizar la institucionalización de la filosofía de policía comunitaria, la PNC estableció en 2009 la doctrina institucional sobre policía comunitaria, que constituye el marco de referencia común en materia de formación, planificación y organización de los servicios operativos de la institución policial (PNC, 2010, citado en IUDOP, 2014, p. 799).

17 Las cinco fases son las siguientes: 1. capacitación del personal de las dependencias policiales; 2. elaboración de diagnósticos locales; 3. planificación operativa; 4. ejecución de planes operativos; y 5. supervisión y evaluación (interna y externa).

18 Cabe destacar que, a partir de la elaboración de dichos diagnósticos, la patrulla responsable de determinado subsector debe elaborar mapas integrados que reflejen, entre otros aspectos, factores de riesgo situacional y factores sociales de protección. 
la planificación operativa en los territorios, en la que integra actividades de represión del delito e inteligencia, así como acciones en materia de "prevención comunitaria", que es aquella que combina la realización de acciones de prevención situacional y acciones socio-preventivas ${ }^{19}$.

Desde esos espacios de articulación entre la PNC y otros actores locales que privilegia la implementación de la FPC, los gobiernos locales y sus brazos operativos los CAM pueden tener una participación activa en la planificación de acciones dirigidas a garantizar la seguridad en sus municipios.

\section{Algunas consideraciones sobre las potenciales sinergias entre CAM y PNC para asegurar un efectivo control social y del delito}

En los últimos años, El Salvador ha sido considerado uno de los países con las más altas tasas de violencia homicida en el mundo. Para 2015, cerró con una tasa de 103 homicidios por cada 100 mil habitantes. Más allá del dato duro, la "muerte cercana" con que la población se ha acostumbrado a convivir por el fenómeno pandilleril, ha llevado a que el Estado pierda el monopolio de la fuerza, sino que también es posible identificar "espacios de soberanía contestada" por el dominio territorial violento que ejercen las pandillas.

Las estructuras pandilleriles se han expandido por todo el territorio nacional disputando, en algunos casos, la autoridad y el control territorial al Estado salvadoreño. Las maras, en su expresión más local (clicas o canchas), ejercen control, a partir de la intimidación y la violencia, en las comunidades que dominan para conservar esos territorios y garantizar la reproducción de la economía ilícita criminal basada en el narcomenudeo, el sicariato y las extorsiones, principalmente.

En ese sentido, es de suma importancia buscar alternativas viables para fortalecer la presencia y control estatal en esos territorios donde la autoridad del Estado es débil y que se rigen por otro tipo de leyes, como el "ver, oír y callar". Con ese objetivo, es necesario plantear y debatir nuevas estrategias integrales que, paralelas a los esfuerzos de la PNC en la represión, el combate y la prevención del delito, otras instituciones —como los gobiernos locales- deberían aportar desde su naturaleza políticojurídica, en la tónica del desarrollo local-territorial.

19 Según el Plan para implementar la filosofía de policía comunitaria (2010b) se entenderá por "prevención comunitaria" a la colaboración que la Policía ofrece en sus planes al resto de actores comunitarios, en la ejecución de iniciativas preventivas, aplicando una lógica combinada de lo social con lo situacional, sin abandonar los aspectos represivos, dentro del marco legal. 
Uno de los principales puntos de coincidencia entre los entrevistados para este estudio fue la identificación del potencial rol que podrían tener los CAM en apoyo a la seguridad pública, aunque es importante remarcar que dichas potencialidades se encontraban matizadas por limitantes de tipo legal y normativo. Sin embargo, más allá del aspecto jurídico, se evidenció que, en la práctica, los CAM cumplen un papel en materia de seguridad. Ello hace posible argumentar que dichos cuerpos, desde una visión de gobernabilidad (local), pudiesen cumplir un rol más estratégico y proactivo en la seguridad pública. Aquí se vislumbran algunos puntos de encuentro entre sus funciones y las estrategias que lidera el gobierno central en materia de control social y prevención situacional del delito. A continuación, se plantean algunas rutas generales donde podrían potenciarse o mejorarse esas sinergias estratégicas entre los CAM y la PNC para hacer más efectivo el rol de los primeros en materia de seguridad pública.

\section{1. Área jurídica}

En el plano jurídico se abren importantes posibilidades para reformas, creación o replanteamiento de algunas normativas relacionadas con la formación, los requerimientos técnicos generales de los CAM o policías municipales, así como de su relación funcional con la PNC.

Los actores clave entrevistados coincidieron en que, en la actualidad, la coordinación entre los concejos municipales y la PNC, para acciones conjuntas, se encuentra bastante determinada por la particularidad de las relaciones entre los funcionarios de turno. En este sentido, consideran necesario algún tipo de legislación que establezca de manera clara cómo deben ser estas relaciones, y que obligue legalmente a entablarlas, para que no dependan de la voluntad política los funcionarios de turno.

Siguiendo con la lógica anterior, los expertos también señalaron que sería muy útil una normativa general que contemplara al menos los siguientes aspectos generales de los CAM: su formación y profesionalización, sus distintivos, estructura organizativa y equipamiento, y las formas generales de relación y colaboración con la PNC y otras instituciones. Observan que al no estar normados estos aspectos quedan a criterio de cada municipalidad, dificultando la tarea de tecnificar el accionar de los CAM, minimizando o limitando el impacto en sus tareas de seguridad públicas.

La necesidad de una legislación que norme de manera general y uniforme la formación y profesionalización de los CAM es destacada por los entrevistados, ya que debido a diversos motivos — presupuestarios, legales o políticos- en la actualidad la formación de los CAM es deficiente, y no hay suficiente claridad en las diversas leyes relacionadas en estos aspectos. Si bien la Ley de los Servicios Privados de Seguridad relaciona, en ciertos aspectos, la formación de los CAM con la ANSP, este marco legal aún es 
endeble y no permite avanzar hacia una formación que profesionalice y estandarice a los CAM de los 262 municipios.

Por otra parte, los actores entrevistados coinciden en que doctrinariamente los términos policía comunitaria o policía municipal son ampliamente aceptados, por lo que, más allá del Acuerdo Político de 1992, que reservó el término "policía" para la naciente PNC, la concepción de policía municipal tiene sus propios significados y marcos de acción en los estándares internacionales. También coinciden en que la implementación de la policía comunitaria, como componente fundamental en una estrategia de país en materia de seguridad, es el modelo ideal para sacar más provecho a las interacciones entre los CAM y la PNC, colocando el rol de los CAM no como agentes gendarmes, sino como promotores y gestores de seguridad y desarrollo, que juegan o deberían jugar un rol clave en las tareas de prevención situacional.

La prevención es el aspecto de la seguridad pública en la que, según los expertos entrevistados, deberían funcionar los CAM, para lo cual una mejor sinergia con la PNC es de primordial importancia. Coinciden en que no deben adherirse atribuciones legales a los CAM en aspectos de represión o investigación; estas funciones deben estar reservadas para la PNC, respetando el acuerdo y la reforma constitucional de 1992, pues tecnificar y mejorar estas funciones en la misma PNC es una tarea difícil, por lo que agregárselas a otro cuerpo institucional sería probablemente no solo equivocado desde lo jurídico, sino además abrirí a la puerta para arbitrariedades, errores de procedimiento y, en general, mayor violación de derechos humanos.

\subsection{Formación y profesionalización de los CAM}

Los especialistas entrevistados concuerdan en que la formación y la profesionalización de los CAM deben mejorar mucho por, al menos, las siguientes razones o motivos:

a. La formación - tanto en lo jurídico-institucional como en lo técnicopolicial- que reciben los CAM depende del criterio y de la autoridad municipal de turno, por lo que carece de sistematicidad. Ha habido algunas excepciones, como San Salvador y Santa Tecla, donde la formación en técnicas de abordaje policial ha tenido una inversión significativa, sobre todo para enfrentar el ordenamiento de los centros históricos y el desalojo de las ventas ambulantes o de calle. No obstante, se requerirá una mayor voluntad política y recursos financieros para avanzar en los procesos de profesionalización. Como es el caso del CAM de Santa Tecla que en el marco de su proceso de reestructuración se han creado una serie de unidades especializadas como parte de su estructura organizativa (Unidad de Bomberos; Unidad Rural; Unidad de Turismo, Unidad de Tránsito, Protección de Personalidad Importantes; Unidad 
de Reacción, entre otras), lo cual implicará capacitar a los agentes en funciones que van más allá de la función tradicional de vigilancia y cuido del patrimonio municipal.

b. La profesionalización de los CAM es prácticamente nula, y en algunos casos manifestados por los entrevistados, los agentes municipales en funciones buscan la formación de la ANSP20 con el objetivo de capacitarse para tener un mejor currículo que les permita el ingreso laboral a empresas de seguridad privada.

c. La profesionalización también se ve minada por la inexistencia de mecanismos claros de ingreso, ascenso y salida de los CAM, así como por la inexistencia de un escalafón, que les permita a los agentes municipales contemplar su función como una profesión, quedando en muchas ocasiones sujetos a los vaivenes electorales.

Ha habido esfuerzos de formación para los agentes del CAM en materia de policía comunitaria. Por ejemplo, el CAM de Santa Tecla fue el primer cuerpo en recibir, en 2011, en el marco del proyecto Ciudad Segura para Convivir, apoyado por el PNUD, cursos de formación en materia de FPC, proceso desarrollado como producto de la alianza establecida entre la municipalidad, la PNC y la ANSP.

\subsection{Potenciales sinergias entre PNC y CAM en un contexto adverso de seguridad}

Sin duda el Estado salvadoreño, frente a la situación adversa por la que atraviesa en términos de seguridad (producto de múltiples factores, entre ellos la debilidad para arraigarse en los territorios), tiene la obligación de recuperar el control y autoridad de los espacios de soberanía contestada. En tal sentido, cualquier estrategia que implemente para ello debe apuntar a una "presencia estatal constante en el territorio, no solo de los aparatos coercitivos, sino también de aquellas instituciones encargadas de proveer bienes y servicios sociales a la población, actuando todas ellas en forma coordinada" (Casas Zamora, 2012).

En esos esfuerzos en los que resulta necesario activar todo el aparataje estatal para garantizar una oferta pública integral, debe guiarse por un proceso efectivo de territorialización de las políticas públicas que asegure una presencia permanente del Estado y otros actores en los territorios, a partir del cual se avanceen un trabajo coordinado desde el nivel central y municipal en materia de prevención y otras acciones dirigidas al desarrollo local-territorial. Tal como lo concibe la Estrategia Nacional de Prevención

20 Entre 2013 y 2014, el Departamento de Servicios Privados y Estatales de Seguridad de la ANSP capacitó a 772 elementos de los CAM de distintos municipios. 
de la Violencia (Gobierno de El Salvador, 2012), desplegando procesos que generen la suficiente capacidad técnica, programática y financiera para responder a las necesidades concretas y específicas de cada territorio, articulando de manera coherente y eficiente los diferentes niveles de gobierno (nacional, departamental y local) para dar respuesta a las dinámicas que generan violencia y delincuencia.

En esas estrategias de seguridad en las que es necesario fortalecer los mecanismos de articulación y coordinación, se considera clave el rol de los CAM, particularmente en materia de prevención social del delito en el marco de estrategias que se han definido en los últimos años como el Plan El Salvador Seguro ${ }^{21}$, planes de desarrollo territorial, así como en el marco de la implementación de la Policía Comunitaria, medida que la PNC ha implementado con mayor fuerza a partir de 2014 en todo el país.

\section{Los CAM como agentes comunitarios}

La PNC ha reconocido que no puede pretender que la solución a los problemas de violencia y criminalidad se logrará solamente como producto de su esfuerzo y de privilegiar de manera absoluta la represión del delito (Policía Nacional Civil, 2011).

En el marco de la policía comunitaria-que basa su intervención en la capacidad de lograr un acercamiento significativo con la comunidad, tomando un rol importante en la coproducción de seguridad, sobre todo en lo relativo a la prevención de la violencia y la delincuencia (PNC, 2011, p. 11) - se hace posible vislumbrar potenciales sinergias entre los CAM y la PNC. En esta lógica, según la Doctrina institucional sobre Policía Comunitaria de la PNC (2010a), las jefaturas policiales de diferentes niveles jerárquicos deben participar activamente en las estructuras de los comités municipales, para identificar problemas, factores de riesgo del accionar delincuencial, y para elaborar propuestas de solución, en otras palabras, se trata de planes de acción ${ }^{22}$.

21 En enero de 2015, el Consejo Nacional de Seguridad Ciudadana y Convivenciaentregó el Plan El Salvador Seguro, documento que contiene 124 acciones, agrupadas en cinco ejes, fruto de siete mesas técnicas y de consultas territoriales y sectoriales en que participaron diversos sectores del país. Los ejes son los siguientes: i) prevención de violencia; ii) persecución penal; iii) rehabilitación e inserción social; iv) atención y protección a víctimas, y v) fortalecimiento institucional.

22 Algunos municipios han venido elaborando desde hace algunos años planes específicos en materia de prevención de la violencia que son elaborados en conjunto con la PNC. En lo que va de 2016, en el marco del Plan El Salvador Seguro se han elaborado planes específicos que establecen una serie de acciones para detener los ciclos de violencia en los primeros diez municipios priorizados. En dichos planes sobre todo en los componentes de seguridad (referidos a prevención), le han sido encomendadas una serie de actividades a las Alcaldías en línea de fortalecer a los CAM en los sectores que están siendo intervenidos. 
En esa dinámica de complementariedad y responsabilidad compartida, que implica la FPC y la estrategia de seguridad integral que impulsa el gobierno, se pueden identificar algunos puntos de encuentro entre lasfacultades de los CAM y la PNC, tal como se muestra en la figura 2.

Así, teniendo en cuenta las funciones de los CAM y su cercanía con las comunidades, estos cuerpos pueden proveer a la PNC información estratégica de los contextos específicos, que sirvan como insumo para diagnósticos y mapas integrados en los cuales la PNC identifique factores de riesgo ${ }^{23}$ y factores de riesgo situacional ${ }^{24}$ en los distintos sectores y subsectores de implementación de la FPC.

Actualmente es posible identificar algunos avances en la articulación entre los CAM y la PNC en cuanto a la elaboración de diagnósticos y planes, particularmente gracias a la dinámica generada por el trabajo de los Consejos de Prevención de la Violencia a nivel local y municipal. No obstante, se trata de una lógica de trabajo que recién está tomando forma, lo cual demanda fortalecerse ya que al no estar arraigada una cultura de planificación (tanto a nivel central como local) se pueden identificar resistencias para trabajar de manera coordinada en los territorios.

Avanzar en la fase de planificación territorial (de forma articulada y coordinada a nivel interinstitucional) es aún uno de los desafíos que debe superar la PNC para dar un salto de calidad en la implementación de la FPC. Una filosofía que se basa en la corresponsabilidad y coparticipación de los distintos actores locales (entre ellos los CAM) en la gestión de los problemas que afectan a las comunidades.

23 Según la OMS, existe una serie de factores de riesgo en cuatro niveles: individual, relacional, comunitario y social. En el nivel individual, se encuentran los factores biológicos y de la historia personal que pueden influir en los comportamientos individuales, es decir, algunas características como la edad, el nivel educativo, pero también el uso de drogas y el comportamiento agresivo o el haber sufrido maltrato. El nivel relacional tiene que ver con el examen de las relaciones sociales con personas cercanas: familia, pareja, amigos, etc. La OMS sostiene que la violencia exhibida por parte de algunos de estos podría fomentar la práctica de otros actos violentos. El nivel comunitario se refiere a las características del comportamiento en las escuelas, lugares de trabajo y en el vecindario; algunas variables relacionadas son el hacinamiento, la densidad poblacional, el desempleo, la facilidad de acceso a drogas y armas, etc. Y el último nivel de sociedad guarda relación con "Ios factores que crean un clima de aceptación de la violencia, los que reducen las inhibiciones contra esta, y los que crean y mantienen las brechas entre distintos segmentos de la sociedad, o generan tensiones entre diferentes grupos" (OMS, 2002).

24 Factores que tienen relación con el entorno físico-ambiental que vuelven más probable la realización de delitos, contribuyendo a la peligrosidad de las áreas de responsabilidad (Policía Nacional Civil, 2011). 


\section{Figura 2: Competencias del CAM y PNC en un trabajo de policía comunitaria}

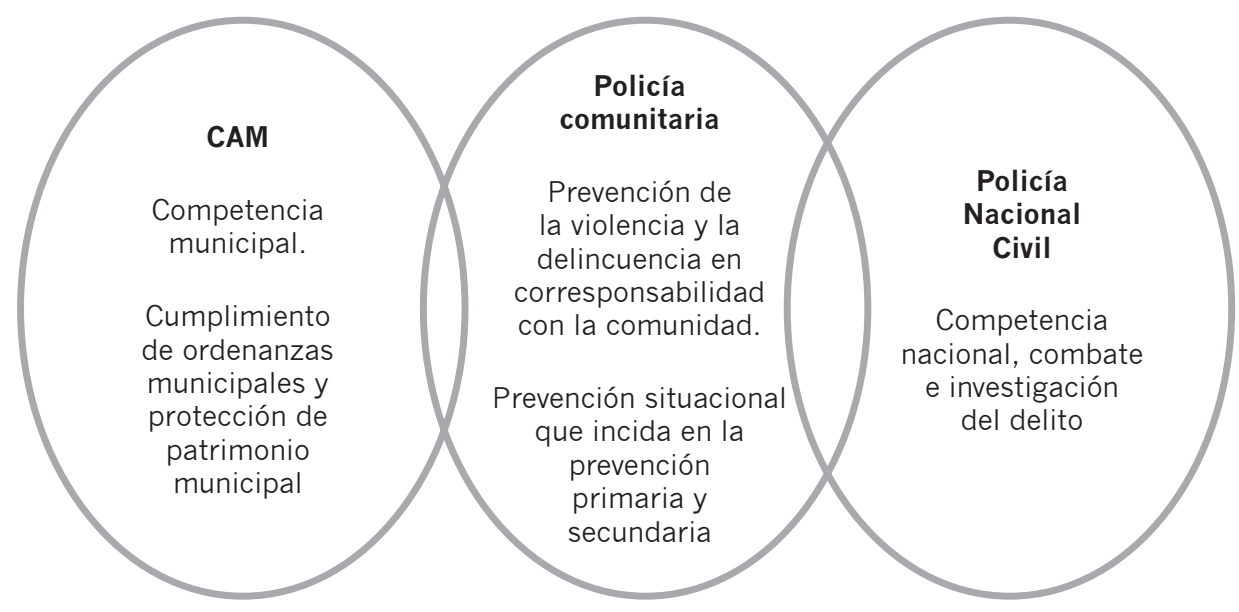

Fuente: Elaboración propia sobre la base de PNC (2011).

En las fases de diagnóstico y de planificación operativa, que establece la implementación de la FPC, el rol de los CAM resulta fundamental. Por su trabajo territorial, estos cuerpos conocen la realidad de las comunidades y pueden ofrecer insumos importantes en la elaboración de diagnósticos, la identificación de factores de riesgo, los mapeos integrados y la planificación operativa.

El recurso humano con el que cuentan los $\mathrm{CAM}^{25}$, y particularmente su organización, despliegue y logística, puede estar definida a partir de la sectorización y subsectorización con la que ha trabajado la PNC en los últimos años, dando prioridad a los sectores donde se implementa la policía comunitaria ${ }^{26}$. En el caso del CAM de San Salvador, por ejemplo, su despliegue podría trazarse en función a fortalecer el trabajo que la delegación policial de San Salvador Centro realiza en las 7 zonas, 41 sectores, 797 subsectores y 487 subsectores (donde se implementa policía comunitaria con un estimado de 705 policías).

EI CAM de San Salvador, que cuenta con 896 efectivos, puede organizar su despliegue en función de priorizar aquellos subsectores donde la presencia estatal es aun débil, así como en aquellos lugares donde la PNC ha logrado insertarse comunitariamente para fortalecer y mantener el trabajo que se

25 Según información para este estudio, el número de elementos de los CAM en cada municipio a diciembre de 2015 es el siguiente: Santa Tecla, 296 efectivos;San Salvador, 896 efectivos.

26 A octubre de 2016, la PNC estima una cobertura nacional aproximada del $70 \%$ en la implementación de la FPC. De los 2,220 sectores definidos en el Sistema de Prevención Delincuencial existen11,292 subsectoresde los que en 7,963 de ellos se trabaja con policía comunitaria (Policía Nacional Civil, 2015). 
esté realizando. Así también, el apoyo potencial que pueden brindar los elementos del CAM en apoyo a tareas de seguridad puede ser estratégico si se focaliza en sectores donde se concentra la incidencia delictiva, como sucede en ciertas zonas del centro histórico de San Salvador. Una zona que, en teoría, debería representar el centro económico, político, cultural y social del país. No obstante, la realidad muestra un centro capitalino inundado por el caos, el desorden, calles intransitables tomadas por el comercio informal, patrimonio arquitectónico e histórico deteriorado, abandono de su función habitacional, inseguridad y violencia producto de la dominación territorial ejercida por las pandillas MS y Barrio $18^{27}$.

\section{Mapa 1. Sectorización San Salvador Centro}

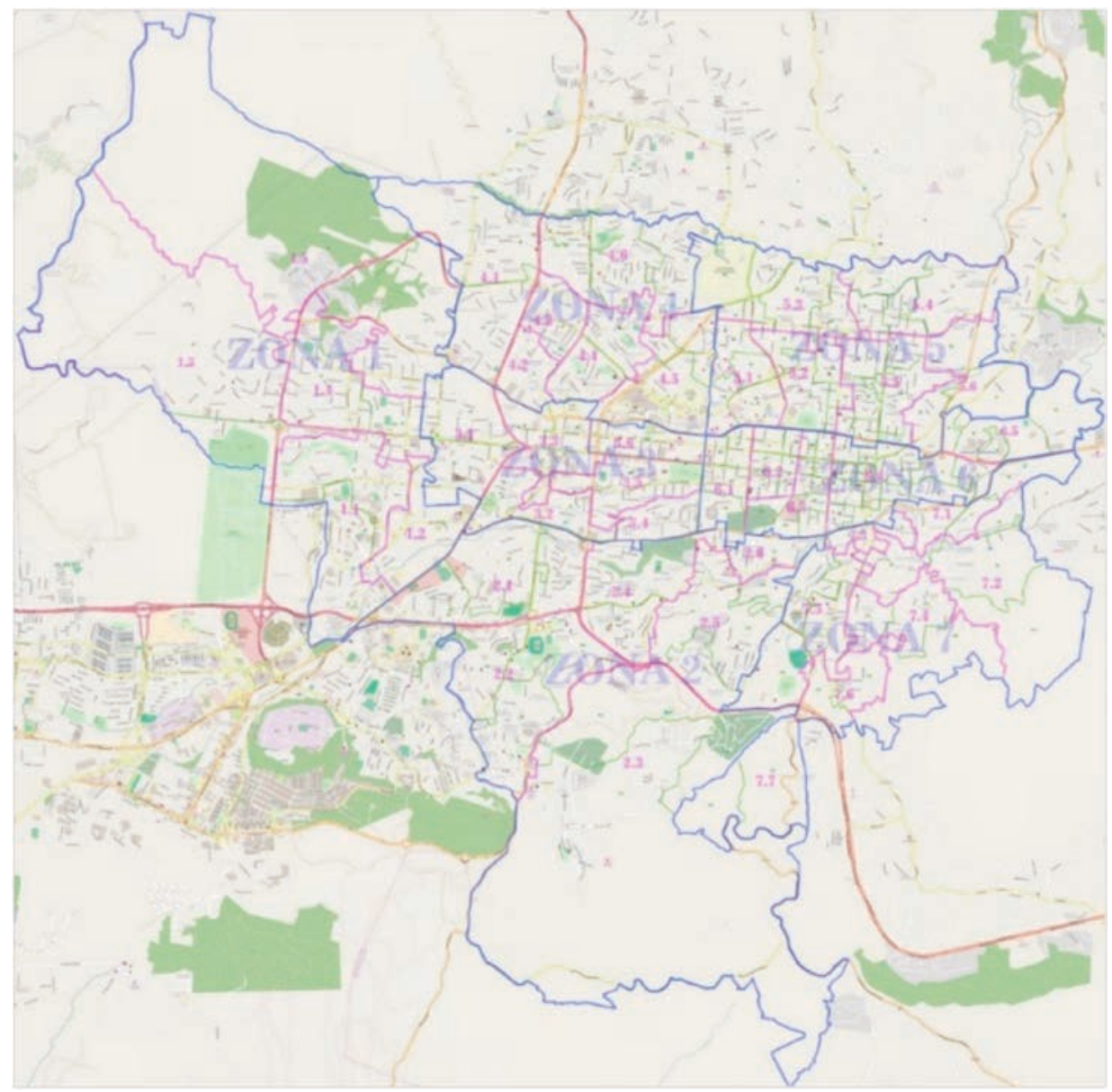

Fuente: PNC, 2016.

27 Para mayores referencias sobre el control territorial ejercido por las maras en el centro de San Salvador, véase Martínez (2015). 
Ese desorden, la cultura de la ilegalidad que se respira en los mercados, los callejones donde se venden artículos robados y las calles saturadas por las ventas informales se han convertido en espacios para la reproducción social de la economía ilegal-criminal de "baja delincuencia" (López Ramírez, 2012), constituyéndose en un terreno fértil para que proliferenotras actividades criminales como robos, hurtos y homicidios, delitos que se han convertido en el pan de cada día en San Salvador ${ }^{28}$.

Se sabe que en las zonas 5 y 6 (mapa 1 ) se concentra el mayor porcentaje deincidencia delictiva. Particularmente, en las cercanías del mercado La Tiendona y de la colonia Don Bosco se registrala mayor parte de la violencia homicida del municipio de San Salvador: vendedoras de plátanos y mariscos, comerciantes de papas, vigilantes y cargadores de bultos fueron algunas de las 36 personas asesinadas en 2015.

Para dar un tratamiento más efectivo en ese tipo de contextos-donde estructuras criminales están bien arraigadas y controlan una base social ligada al comercio informal- se necesita en una etapa inicial, como ya se mencionó, una estrategia integral en la que el Estado recupere el control y la autoridad de esas porciones de territorios. En esa línea, en los últimos meses, las autoridades de Justicia y Seguridad Pública con el apoyo de la Fuerza Armada han lanzado planes de intervención, como el plan Alacrán para asegurar mayor presencia del Estado en lugares complicados por la presencia de pandillas. No extraña entonces que los mercados, las calles y demás espacios públicos sean los principales lugares donde la población se siente más insegura, como revela la figura 3.

Si bien se trata de esfuerzos positivos, parecería muchas veces que son medidas concentradas en lograr la baja de homicidios. Por ello es necesario dirigir los esfuerzos para que apuesten por la recuperación del control territorial por parte del Estado y que no solo se concentren en la represión y el combate directo al crimen. Es decir, que una vez que se logra estabilizar las zonas en control de actores criminales y violentos, la estrategia debe acompañarse no solo de presencia policial permanente, sino de una fuerte inversión del Estado en diferentes áreas, particularmente en las sociales y económicas.

28 Para 2014 este municipio registró 336 homicidios que en alto porcentaje se cometen con armas de fuego. 


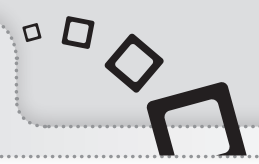

\section{Mapa 2. Ubicación de la zona aledaña al mercado La Tiendona (zona 6)}

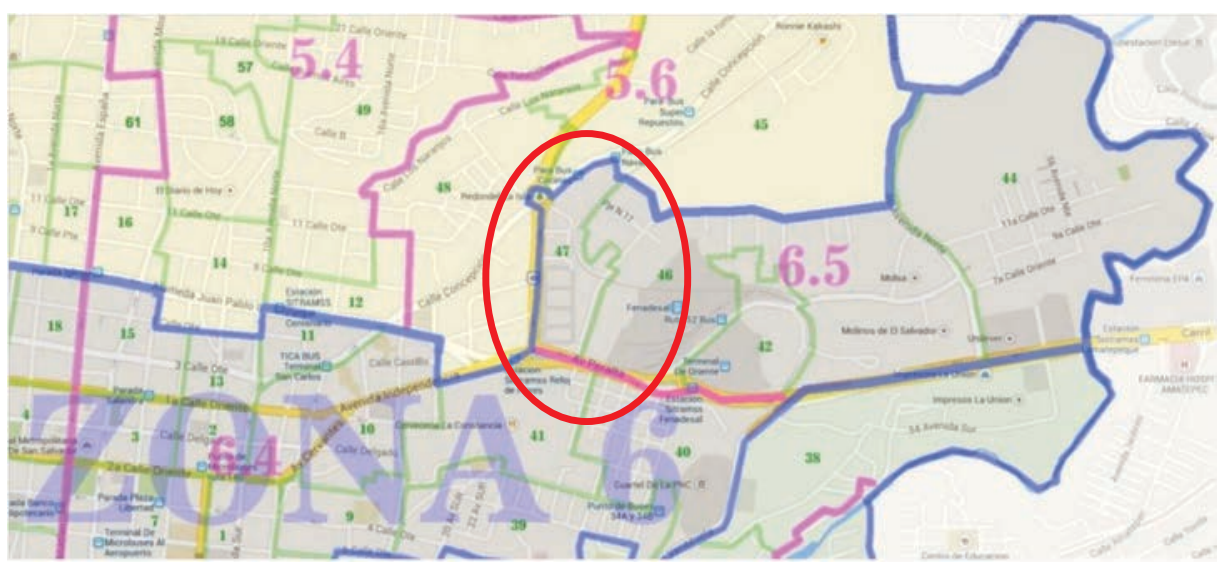

Fuente: PNC, 2016

Figura 3: Percepción de inseguridad ciudadana según lugarfrecuentado (a nivel nacional)

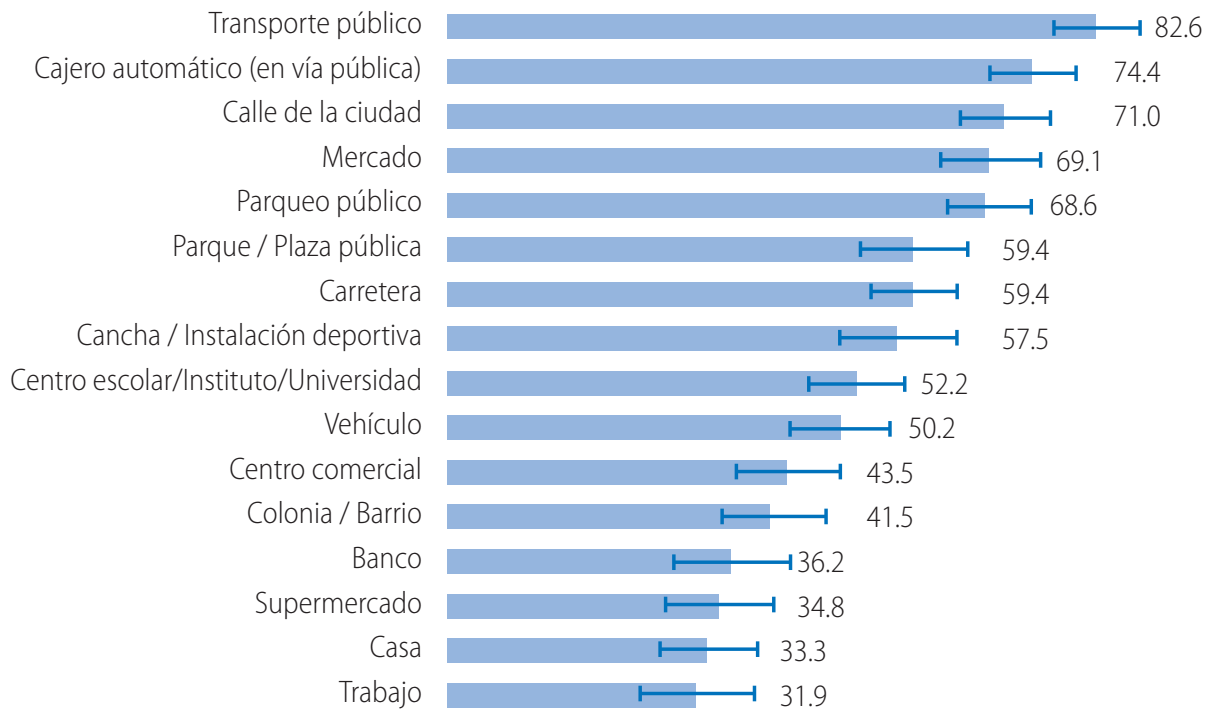

Percepción de inseguridad

Barras de error $95 \%$ IC

Fuente: Observatorio Ciudadano. Encuesta Nacional de Victimización y Percepción de

Seguridad, 2012. 
Así, se trata de estrategias que deben estar basadas en el binomio seguridad-desarrollo y en mecanismos de articulación interinstitucional y sectorial donde confluyan diferentes instituciones y actores en los territorios. Sin duda, en esas estrategias, los gobiernos municipales tienen un peso importante, concretamente a través de los CAM, sobre todo en lo que se refiere a la recuperación y ordenamiento de las ciudades que pueden tener un rol más protagónico en la prevención y el fortalecimiento del trabajo con las comunidades en el marco de la doctrina de la FPC, en coordinación con PNC.

Así lo evidenció la experiencia de la colonia San José del Pino en Santa Tecla, una de las zonas más peligrosas y estigmatizadas por el fenómeno de pandillas en dicho municipio: "la situación era tan crítica que los visitantes no podían entrar, así como los ruteros o vendedores y distribuidores mayoristas (...). La municipalidad, consciente de esta situación, asumió el reto de revertir esta realidad decidiendo intervenir de manera integral a través de acciones orientadas a fortalecer los factores socioculturales y económicos (...) el proceso de intervención se inició a finales de 2012, cuando después de haber intervenido operativamente en una acción preventiva a finales de 2011, el Cuerpo de Agentes Municipales, en coordinación con la PNC, se instalaron con presencia permanente en la casa comunal de la colonia, trabajando con un enfoque de filosofía de policía comunitaria". Ello permitió la entrada de otras instituciones del gobierno central y local para realizar obras dirigidas a transformar la calidad de vida de los habitantes de dicha comunidad.

\section{Recomendaciones}

\section{1. Área jurídica: Posibles rutas de abordaje}

Si bien la Ley de Contravenciones delimita las áreas de acción y competencias de los CAM, también es cierto que lo respectivo a sus uniformes, equipamiento-armamento, entrenamiento, escalafón, entre otros aspectos, no se encuentra regulado por ninguna ley, sino por ordenanzas municipales que, debido a su naturaleza, generan una dispersión importante. Esto mina las posibilidades de contar con CAM profesionales, que tengan una relación más fluida, efectiva y certera con la PNC en las comunidades.

En tal sentido, se propone aquí iniciar la discusión sobre una legislación secundaria, de aplicación general para todas las municipalidades, que regule como mínimo los aspectos mencionados (uniformes, equipamientoarmamento, entrenamiento y formación, escalafón, etc.) para elevar el nivel de profesionalización de los CAM, y para fortalecer su rol y relación con la PNC. Esta, que, en su modelo de policía comunitaria, necesita de CAM que se encarguen de identificar y trabajar aquellos factores de riesgo vinculados a sus áreas de competencia (ordenamiento territorial, espacios 
públicos, regulación de comercios, seguridad vial, licencias para ventas de bebidas embriagantes, cuido del patrimonio y espacio público), que cuando se acumulan y no son debidamente abordados pueden convertirse en verdaderos problemas de seguridad pública.

Por otra parte, es necesario un marco normativo que establezca las formas de relacionarse e interactuar entre los mandos locales de la PNC y las autoridades municipales. Esto con el fin de evitar la duplicación de mesas de coordinación, redes de trabajo, grupos de tarea conjunta, que puedan resultar inoperantes o menos efectivas; pero también para evitar que dichas relaciones e interacciones, necesarias en el territorio entre la PNC y el CAM, dependan de las emotividades o subjetividades de las autoridades municipales y de las locales de la PNC. Es también necesario establecer claramente las formas y la periodicidad, así como los mecanismos para rendir cuentas, de modo que puedan ser fácilmente exigibles por la población (control vertical), otras instituciones (control horizontal) o por ambos (diagonal).

En la formación y profesionalización de los CAM se encontró una debilidad en el plano jurídico, pues en la actualidad se encuentra laxamente contemplada en la Ley de los Servicios Privados de Seguridad. En tal sentido se propone abrir la discusión política ante la opinión pública sobre el rumbo y los modelos (los para qué) de los CAM en la actual situación que vive el país. A partir de dicha discusión será importante definir este rumbo, esa policía municipal o cuerpos municipales, que necesita el país, para plantear una formación y profesionalización que responda a ese nuevo paradigma. En esta área es pertinente tener en cuenta otros aspectos, como el presupuestario (quién debe pagar o cómo debe financiarse la formación de los CAM); los tiempos, las áreas de formación y la institución encargada de dicha formación (que podría ser la ANSP); la profesionalización de los CAM (sus requisitos y proceso de ingreso; control interno; sus formas de retiro; los mecanismos de rotación, ascenso y/o degradación, entre otros).

Si tal como fue planteado en el apartado anterior, los CAM juegan o deberían jugar un rol aún más estratégico en la implementación de la FPC, entonces deben plantearse un nuevo marco jurídico que responda a esa función, situándola más allá de los vaivenes de los cambios de partido político tanto en la administración pública nacional como en la municipal.

\subsection{Formación: posibles rutas de abordaje}

La necesidad de crear una academia para agentes municipales, o de ampliar las funciones de la ANSP en una nueva área o dirección para que los incorpore y forme, es una de las líneas de abordaje que deben ser estudiadas y debatidas. Entre las ventajas de que la ANSP asumiera estas funciones se encuentran la experiencia y capacidad instalada de 
la institución, así como la posibilidad de que priorice y compatibilice la formación de los CAM dentro de la lógica depolicía comunitaria, poniendo énfasis en formarlos para el control y abordaje de los factores de riesgo contemplados en la Ley de Contravenciones. Si bien ya se han realizado algunos cursos sobre policía comunitaria dirigidos a estos cuerpos, aun se trata de esfuerzos dispersos y no institucionalizados.

Debe tenerse en cuenta que tanto la posibilidad de la creación de una academia municipal—que podría estar a cargo del Instituto Salvadoreño de Desarrollo Municipal (ISDEM)—como la de ampliarlas funciones de la ANSP implican la necesaria creación o refuerzo de un rubro presupuestario. La ley del FODES podría cambiarse o reformarse para que las municipalidades contaran con los recursos por la vía legal para la formación de los CAM. Para ello sería necesario justificar legalmente el rol del CAM como parte del desarrollo social de los municipios. Por otra parte, podría contemplarse la creación de un impuesto municipal para el mantenimiento y formación de los CAM, por medio de su inclusión en la Ley General Tributaria Municipal.

Por otra parte, debe discutirse un diseño administrativo que modele el perfil del agente municipal, para que este funcione de manera institucional y dependa menos de los cambios político-electorales. De lo que se trata, entonces, es de discutir la posibilidad de crear una carrera de agente municipal o policía municipal, que, además, permita que las municipalidades con menos presupuesto también cuenten con un mínimo de agentes municipales profesionales a su disposición y bajo su mando. Esto a su vez requeriría la discusión sobre los aspectos salariales, que podrían llevarse a un escalafón que diera soporte a nivel nacional a los agentes de carrera.

En noviembre de 2015, desde la División de Estudios de la ANSP se elaboró un proyecto que llena, en buena medida, los vacíos en cuanto a la formación específica que deberían recibir los agentes municipales. Se trata de un curso de formación básica que incluye contenidos en tres áreas de estudio: jurídica, humanística y policial29, agregándose una actividad específica de teoría y práctica sobre la elaboración de mapas de riesgo (ANSP, 2015).

29 En el área jurídica se incluyen módulos sobre policía municipal y acercamiento ciudadano; intervención en hechos relacionados con infracciones a las ordenanzas municipales; detenciones y privaciones de libertad en flagrancia; aplicación de leyes medioambientales, entre otros. En el área policial se presta atención a temáticas sobre policía municipal y patrullajes comunitarios y de prevención. En el área humanística se incluyen cursos para fortalecer las habilidades sociales a fin de mejorar la inserción comunitaria, así como aspectos relativos a cultura de paz y equidad de género. 


\subsection{Construir mayores sinergias entre CAM-PNC: recuperar el territorio y construir tejido social}

Si bien en un apartado anterior se plantearon ejemplos de colaboración entre CAM y PNC, que actualmente se dan en materia de seguridad pública - en las áreas de prevención y convivencia ciudadana-, se considera que los CAM tienen enorme potencial para apoyara la PNC en materia de prevención primaria y situacional.

El contexto actual es propicio para desarrollar mayores sinergias entre CAM y PNC. Por la naturaleza, las características y las funciones que realizan en la práctica los CAM, su rol debe ser potenciado en el marco de estrategias amplias de seguridad pública y recuperación del control territorial y social por parte del Estado. El rol de los CAM actualmenteque incluye el mantenimiento del orden, la seguridad patrimonial, el trabajo con las comunidades en prevención y convivencia- debería ser potenciado y fortalecido para acompañar a la PNC y demás instituciones del nivel nacional y local en los esfuerzos para recuperar esa soberanía contestada en algunos territorios y en la implementación de aquellas acciones complementarias sobre la base de estrategias de seguridad integral y desarrollo territorial.

En tal sentido, se considera que los CAM pueden asumir atribuciones que vayan más allá de velar por la seguridad patrimonial, asignándoles funciones complementarias en áreas tales como: la regulación del tráfico vehicular; el apoyo a la seguridad del transporte público y seguridad vial; la inspección y regulación de negocios (función que ya realizan, pero en la cual es importante fortalecer capacidades en relación con el contrabando y evasión fiscal), mantenimiento del orden, asistencia en casos de casos de catástrofes provocadas por eventos naturales, entre otras.

Se podría pensar que, frente a la magnitud del problema de inseguridad por el que atraviesa El Salvador, los esfuerzos en materia de prevención, policía comunitaria y trabajo coordinado entre los CAM y PNC constituyen esfuerzos tímidos para frenar la ola delincuencial. No obstante, en el marco de estrategias más amplias, cada una de esas medidas articuladas posee un alto sentido estratégico.

Sin duda, hay que reconocer que los desafíos en términos de inseguridad y desarrollo no son menores. En El Salvador es posible encontrar algunas experiencias de buenas prácticas como el de San José del Pino, caracterizados por contextos de exclusión social, violencia, crimen, control territorial ejercido por pandillas, débil presencia estatal y bajos niveles de cohesión social. Escenarios que advierten sobre la necesidad, en un primer momento, de pacificar territorios, pero que paralelamente requieren la presencia e inversión del Estado (tanto en su expresión nacional y local) 
y otros actores, como ONG, iglesias, empresa privada, para reactivar esos territorios a través de planes de desarrollo integral que se dirijan a transformar y mejorar la calidad de vida de las comunidades.

En ese contexto, el rol de los CAM en la seguridad debe apuntar a una integralidad en sus funciones. Al tratarse de un cuerpo cercano a la población, sus elementos deben tener la capacidad para insertarse e interactuar en los territorios y gestionar las demandas ciudadanas. Desde las experiencias estudiadas, es posible señalar que el trabajo que desarrollan los CAM en San Salvador y en Santa Tecla se dirige a reforzar y fortalecer la presencia del gobierno local en los territorios. Se trata de esfuerzos que claramente se alinean y complementan con estrategias más amplias que ejecuta el Gobierno central como es el Plan El Salvador Seguro pero que no queda claro el grado de articulación.

El entorno adverso de seguridad obliga a que la gestión de la seguridad pública y otros ámbitos vinculados avancen hacia una nueva forma de trabajo en los territorios, lo cual implica mayores niveles de descentralización dando más autonomía a los gobiernos locales. En esa dinámica, los CAM tendrán un rol cada vez más importante, por lo que, para asegurar una coordinación más activa con instituciones como la PNC será necesario superar el limbo jurídico en el que operan.

En ese sentido, será importante definir un marco jurídico-institucional sobre el rol que deben desempeñar estos brazos operativos de los concejos municipales en apoyo a la seguridad pública y en el marco de planes más amplios de desarrollo territorial. El potencial rol de los CAM en las comunidades y a nivel de las ciudades puede concentrarse en los esfuerzos de prevención y convivencia (con especial énfasis en la cultura de paz y legalidad), así como en los procesos de construcción o fortalecimiento del tejido social-comunitario que se ha debilitado debido al contexto de inseguridad y debilidad estatal por el que atraviesa El Salvador durante los últimos años. 


\section{Bibliografía}

Acero Velásquez, Hugo (s.f.). Experiencias exitosas de seguridad en gobiernos locales. Nueva York: OEA. Departamento de Seguridad Pú. blica.

AMUPREV (s.f.). Política Municipal de Prevención y Convivencia Ciudadana deSanta Tecla. Recuperado dehttp:// www.amuprev.org/historias/caso. php?id=19

Arévalo Herrera, L. C. (2009). Informe. Gestión municipal de la seguridad ciudadana en Centroamérica y República Dominicana. Capítulo El Salvador. San Salvador. Recuperado de https://proyectoflacso.files.word press.com/2010/05/informe-finalel-salvador.pdf

Bravo, O. y Marín González, F. (2014). Modelo de desarrollo local para los municipios. Cuadernos del CENDES, 31 (86), pp. 1-26. Recuperado de http://www.scielo.org. $\mathrm{ve} / \mathrm{pdf} / \mathrm{cdc} / \mathrm{v} 31 \mathrm{n} 86 / \mathrm{art02}$.pdf

Casas Zamora, K. (2012). La polis amenazada: (In)seguridad ciudadana y democracia en América Latina y el Caribe. Organización de Estados Americanos

Consejo Nacional de Seguridad Ciudadana y Convivencia (2015). Plan El Salvador Seguro. Gobierno de El Salvador.

Córdova, R. y Seligson, M. (2001). Cultura política, gobierno local y descentralización III - El Salvador. San Salvador: FLACSO.
Dammert, L. (2003). Participación comunitaria en la prevención del delito en América Latina ¿De qué participación hablamos? Delito y Sociedad: Revista de Ciencias Sociales. (18-19), pp. 125-157.

Eissa, S. (2005). Lucha contra el narcotráfico y su impacto en América Latina. Recuperado de http:// www.caei.com.ar/sites/default/ files/02_4.pdf

FUNDE y FUNDAUNGO. (1998) Construyendo un nuevo marco legal para el desarrollo municipal. San Salvador: FES-FUNDE-FUNDAUNGO.

Frühling, H. (2014). Violencia en barrios: Generación de conocimiento para intervencionesfocalizadasterritorialmente. Seguridad Ciudadana en América Latina: Múltiples dimensiones y dilemas políticos, pp. 17. 21. Universidad de Chile.

Garrido, V.; Farrington, D.P. y Welsh, B.C. (2006). The importance of an evidence-based approach in the current Spanishpolicy for crime prevention. Revista Psicothema,18 (3), pp. 591-595.

Hurrell, A. (1998). Seguridad y violencia en América Latina: un análisis conceptual. Revista Foro Internacional, 38(1.151), pp. 19-36.

INTERPEACE. (2014). Santa Tecla, un terreno fértil para la reducción de la violencia. Guatemala: INTERPEACE. 
IUDOP. (2014). La situación de la seguridad y la justicia 2009- 2014. Entre expectativas de cambio, mano dura militar y treguas entre pandillas, 1. San Salvador: UCA.

López Ramírez, A.(2012). La economía ilícita: Una perspectiva desde la reproducción socio-económica. Revista Policía y Seguridad Pública, 2(1), pp. 169-194.

Martínez, Ó. (2015). Los bichos gobiernan el centro. El Faro. http:// www.especiales.elfaro.net/

Morales Peña, J. C. (2011). Propuesta analítica de cinco tesis interpretativas de la violencia estructural y el ejercicio de gobernabilidad en materia de gestión de seguridad pública y prevención de violencia en el Municipio de Santa Tecla. Revista Policía y Seguridad Pública, 1 (1), pp. 55-141.

Morales Peña, J. C. (2012). Nuevos empoderamientos criminales y desafíos globales para los Estados del Triángulo Norte centroamericano y México. Revista Policía y Seguridad Pública, 2 (1), pp. 195-270.

Murcia, W. (2015). Las pandillas en El Salvador: propuestas y desafíos para la inclusión social juvenil en contextos de violencia urbana. Chile: CEPAL

OMS. (2002). Informe Mundial sobre la Violencia y la Salud. Génova, Italia.
Portillo Chinchilla, S. M. (1998). Limitaciones jurídicasen la función del Cuerpo de Agentes Metropolitanos (CAM) de la Municipalidad de San Salvador. Tesis. Universidad de El Salvador. Recuperadodehttp://www. csj.gob.sv/BVirtual.nsf/f8d2a 0 b 5 e e 4651 a 386256 d 44006 c $123 \mathrm{c} / 0024 \mathrm{e} 77640661 \mathrm{f} 8 \mathrm{c} 06$ 2576400075b3b0?OpenDocument

Ruiz Rodríguez, L. (2010). La gestión urbana de la seguridad: Política criminal y municipios. Revista Electrónica de Ciencia Penal y Criminología, 12. Recuperado de http://criminet.ugr.es/recpc/

Smutt, M. (2013). Una mirada a El Salvador. Documento presentado en el seminario What happens when governments negotiate with organized crime? Cases studies from the Americas, Woodrow Wilson International Center for Scholars: Washington D.C.

Taura, E. (2015). Alcaldía de Santa Tecla lanza "Tecla App". 102nueve Periódico digital. Recuperado de http://102nueve.com/noticia/ nacional/alcaldia-de-santa-teclalanza-tecla-app/

Valencia, R. (2016). La cifra de salvadoreños asesinados se dispara un $118 \%$ respecto al inicio de 2015. El Faro. Recuperado de http://www. elfaro.net/ 


\section{Legislación}

Alcaldía Municipal de San Salvador. (1999). Ordenanza Reguladora del Servicio del Cuerpo de Agentes Metropolitanos del Municipio de San Salvador. Decreto N. ${ }^{\circ} 13,26 / 05 / 1999$.

Alcaldía Municipal de Santa Tecla. (2015). Ordenanza Reguladora del Servicio del Cuerpo de Agentes Municipales del Municipio de Santa Tecla. Acuerdo N. ${ }^{\circ}$ 569, 26/11/2015.

Constitución de la República de El Salvador. (1983). Diario Oficial, 234 (281)

Código Municipal. (1986). Diario Oficial, 23 (290).

Ley Orgánica de la Policía Nacional Civil. (2001). Diario Oficial, 234 (281).

Ley Marco para la Convivencia Ciudadana y Contravenciones Administrativas. (2012). Diario Oficial, 80 (391).

Ley Orgánica de la Policía Nacional Civil de El Salvador. (1992). Diario Oficial, 144 (316).

Ley de los Servicios Privados de Seguridad. (2001). Diario Oficial, 18 (350).

Ley Orgánica de la Academia Nacional de Seguridad Pública.(2001). Diario Oficial, 42 (314).

Ley de los Servicios de Seguridad del Estado, Instituciones Autónomas y de las Municipalidades. (2001). Diario Oficial, 18 (350).
Ley de Creación del Fondo para el Desarrollo Económico y Social de los Municipios. (1988). Diario Oficial, 42 (342).

Ley Orgánica del Instituto Salvadoreño de Desarrollo Municipal. (1987).Diario Oficial, 52 (294).

Ley General Tributaria Municipal. (1991). Diario Oficial, 242 (313).

Ordenanza para la Prevención de la Trata de Personas en el Municipio de Santa Tecla (2013). Diario Oficial, 400 (119).

\section{Documentos institucionales}

Alcaldía Municipal de San Salvador. (2011). Política Municipal de Convivencia, Mediación y Seguridad Ciudadana. Recuperado de http:// www.sansalvador.gob.sv/

ANSP. (2015). Proyecto del Curso Básico para el CAM. Documento bo. rrador. División de Estudios, ANSP.

Gobierno de El Salvador. (2012). Estrategia Nacional de Prevención de la Violencia. Recuperado de http:// www.aecid.org.sv/wp-content/ uploads/2013/07/ENPV-Final-12. Nov-2012.pdf?82a9e7

Ministerio de Justicia y Seguridad Pública. (s. f.). Política Nacional de Justicia, Seguridad Pública y Convivencia. Recuperado de http://www. aecid.org.sv/wp-content/uploads /2014/01/Poli\%C2\%B4tica-Nacio nal-de-Justicia21.pdf?82a9e7 
Policía Nacional Civil (2010a). Doctrina Institucional sobre Policía Comunitaria.

Policía Nacional Civil. (2010b). Plan para implementar la Filosofía de Policía Comunitaria.

Policía Nacional Civil. (2011). Manual de Formación de Policía Comunitaria de El Salvador. 2. ${ }^{a}$ edición.

Policía Nacional Civil. (2015). Avances y lecciones aprendidas en la implementación del nuevo modelo policial basado en la filosofía de policía comunitaria a nivel nacional. Presentación del director general de la PNC en el seminario-taller internacional sobre experiencias lo cales de buenas prácticas y lecciones aprendidas en la implementación de modelos de policía orientados a la comunidad. San Salvador, octubre. 
